\title{
Study of the tensile and impact energy absorption properties of hybrid bast and basalt fiber composites and the effect of basalt fibers size at the mechanical properties
}

YOUSUF PASHA SHAIK ( $\sim$ yousufpashashaik@gmail.com )

Hochschule Kaiserslautern https://orcid.org/0000-0002-8901-4630

Vijay Bhaskar Narlakanti

Hochschule Kaiserslautern

Jens Schuster

Hochschule Kaiserslautern

\section{Research Article}

Keywords: Fibre Reinforced Composites, Natural Fibres, Charpy Testing, Tensile Testing

Posted Date: June 7th, 2021

DOl: https://doi.org/10.21203/rs.3.rs-596673/v1

License: (c) (1) This work is licensed under a Creative Commons Attribution 4.0 International License.

Read Full License 


\title{
Study of the tensile and impact energy absorption properties of hybrid bast and basalt fiber composites and the effect of basalt fibers size at the mechanical properties
}

\author{
Yousuf Pasha shaik, Vijay Bhaskar Narlakanti, Jens Schuster
}

\begin{abstract}
Natural Bast fiber reinforced polymer composites are attractive because of their renewability and environment friendliness. Therefore, in this work, the mechanical properties of these composites have been tried to improve by adding basalt fibers. The fiber mats were prepared by carding. After press molding, the tensile and Charpy mechanical properties of compression molded samples were studied. Moreover, the influence of basalt fibers with two different sizes was studied at the mechanical performance of the composites.

Improvement of mechanical property profile of natural fiber (bast) reinforced polymer composites is carried out by hybridization with basalt fibers.
\end{abstract}

Keywords: Fibre Reinforced Composites, Natural Fibres, Charpy Testing, Tensile Testing. 


\section{$\underline{\text { Abbrevations }}$}

1. PP - Poly Propylene

2. PE - Polyethylene

3. ABS - Acrylonitrile Butadiene Styrene

4. LDPE - Low-density polyethylene

5. HDPE - High-density polyethylene

6. MFR - Melt Flow Rate

7. MFI - Melt Flow Index

8. KF - Kenaf \& Flax

9. DBF - Deutsche Basalt Fibre

10. FT - Fibrax Basalt Fibre 


\section{INTRODUCTION}

The increase in environmental consciousness and community interest, the new environmental regulations and unsustainable consumption of petroleum, led to thinking of the use of environmentally friendly materials. Natural fiber is considered one of the environmentally friendly materials which have good properties compared to synthetic fiber. A late current industry research identified that the worldwide natural fiber reinforced polymer composites industry sector reached U\$2.1 billion in 2010. Current pointers are that interest in NFPCs industry will keep on growing quickly around the world. The utilization of NFPCs has expanded considerably in the shopper merchandise as developing industry sectors throughout the last few years. As indicated by evaluations, over 5 years (2011-2016), the NFPCs industry is estimated to grow $10 \%$ worldwide.

Natural fibers in simple definition are fibers that are not synthetic or manmade. They can be sourced from plants or animals. The use of natural fiber from both resources, renewable and non-renewable such as oil palm, sisal, flax, and jute to produce composite materials, gained considerable attention in the last decades, so far. The plants, which produce cellulose fibers can be classified into bast fibers (jute, flax, ramie, hemp, and kenaf), seed fibers (cotton, coir, and kapok), leaf fibers (sisal, pineapple, and abaca), grass and reed fibers (rice, corn, and wheat), and core fibers (hemp, kenaf, and jute) as well as all other kinds (wood and roots).

\section{Properties of the NFPCs}

There are considerable enhancement and suggestions for the natural fibers that can be implemented in order to enhance their mechanical properties resulting in high strength and structure. Once the base structures are made strong, the polymers can be easily strengthened and improved. There are number of aspects that effects of composite are performance level or activities, of which to name a few are the following;

- orientation of fiber,

- strength of fibers,

- physical properties of fibers,

- interfacial adhesion property of fibers and many more.

But,

Limited mechanical properties for some structural applications. Blending NFRC with glass or carbon fibers improve the property, profile, but decrease the renewable raw material content in the composite [1].

\section{Aim of the project}

Improvement of the mechanical properties of Bast Fiber reinforced composites by hybridization with high performance basalt fibers (inorganic NF). In this project we have tried to improve the properties of these composites by adding basalt to them. Basalt is a natural material and advantage is that it can improve the mechanical properties just like glass fibers. However, the advantage is that basalt is a natural material. Moreover, we have studied two types of basalts, one with a size for thermosets and one with a size for thermoplastics. we have not just tried to improve the properties of composites but have also studied the effect of fiber size at these properties. 


\section{Experimental Procedure}

Polypropylene (PP), also known as polypropene, is a thermoplastic polymer used in a wide variety of applications. It is produced via chain-growth polymerization from the monomer propylene. Polypropylene belongs to the group of polyolefins and is partially crystalline and non-polar. Its properties are similar to polyethylene, but it is slightly harder and more heat resistant. It is a white, mechanically rugged material and has a high chemical resistance.

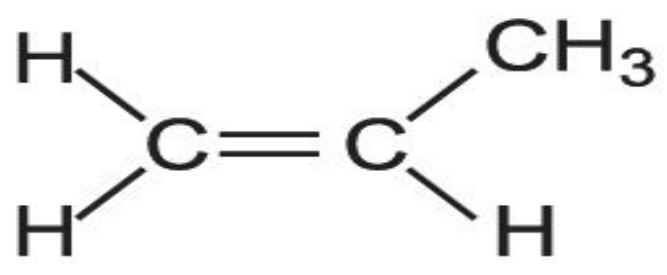

Fig.1 Structure of Propylene [2]

\section{Mechanical properties:}

The density of (PP) is between 0.895 and $0.92 \mathrm{~g} / \mathrm{cm}^{3}$. Therefore, PP is the commodity plastic with the lowest density. With lower density, moldings parts with lower weight and more parts of a certain mass of plastic can be produced. Unlike polyethylene, crystalline and amorphous regions differ only slightly in their density. However, the density of polyethylene can significantly change with fillers. [3] Young's modulus of PP is between 1300 and $1800 \mathrm{~N} / \mathrm{mm}^{2}$. Polypropylene is normally tough and flexible, especially when copolymerized with ethylene. This allows polypropylene to be used as an engineering plastic, competing with materials such as acrylonitrile butadiene styrene (ABS). Polypropylene has good resistance to fatigue. [4]

\section{Thermal properties:}

The melting point of polypropylene occurs in a range, so the melting point is determined by finding the highest temperature of a differential scanning calorimetry chart. Perfectly isotactic PP has a melting point of $171^{\circ} \mathrm{C}\left(340^{\circ} \mathrm{F}\right)$. Commercial isotactic PP has a melting point that ranges from 160 to $166^{\circ} \mathrm{C}\left(320\right.$ to $\left.331^{\circ} \mathrm{F}\right)$, depending on atactic material and crystallinity. Syndiotactic PP with a crystallinity of $30 \%$ has a melting point of $130{ }^{\circ} \mathrm{C}\left(266^{\circ} \mathrm{F}\right)$. [4] Below $0{ }^{\circ} \mathrm{C}$, PP becomes brittle. [5] The thermal expansion of polypropylene is very large, but somewhat less than that of polyethylene. [5]

\section{Chemical properties:}

Polypropylene at room temperature is resistant to fats and almost all organic solvents, apart from strong oxidants. Non-oxidizing acids and bases can be stored in containers made of PP. At elevated temperature, PP can be dissolved in nonpolar solvents such as xylene, tetralin and decalin. Due to the tertiary carbon atom PP is chemically less resistant than PE (see Markovnikov rule). [6] Most commercial polypropylene is isotactic and has an intermediate level of crystallinity between that of low-density polyethylene (LDPE) and high-density polyethylene (HDPE). Isotactic \& atactic polypropylene is soluble in P-xylene at $140{ }^{\circ} \mathrm{C}$. Isotactic precipitates when the solution is cooled to $25^{\circ} \mathrm{C}$ and atactic portion remains soluble in P-xylene. The melt flow rate (MFR) or melt flow index (MFI) is a measure of molecular weight of polypropylene. The measure helps to determine how easily the molten raw material will flow during processing. 
Kenaf: Kenaf [etymology: Persian], [7] Hibiscus cannabinus, is a plant in the family Malvaceae also called Deccan hemp and Java jute. Hibiscus cannabinus is in the genus Hibiscus and is native to southern Asia, though its exact origin is unknown. Kenaf is one of the allied fibres of jute and shows similar characteristics.

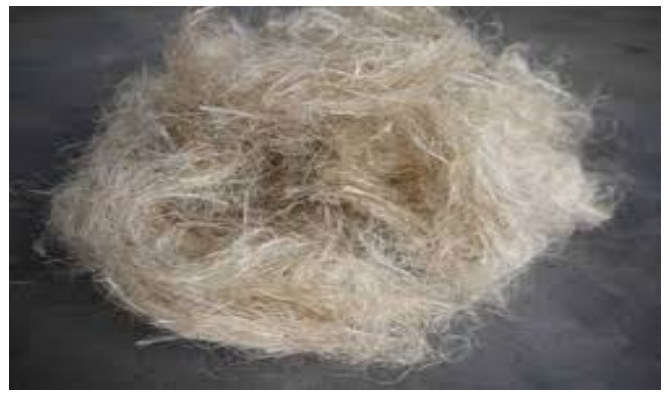

Fig.2 Kenaf Fibre [7]

Flax fiber: It is extracted from the bast beneath the surface of the stem of the flax plant. Flax fiber is soft, lustrous, and flexible; bundles of fiber have the appearance of blonde hair, hence the description "flaxen" hair. It is stronger than cotton fiber, but less elastic. The best grades are used for fabrics such as damasks, lace, and sheeting. [8]

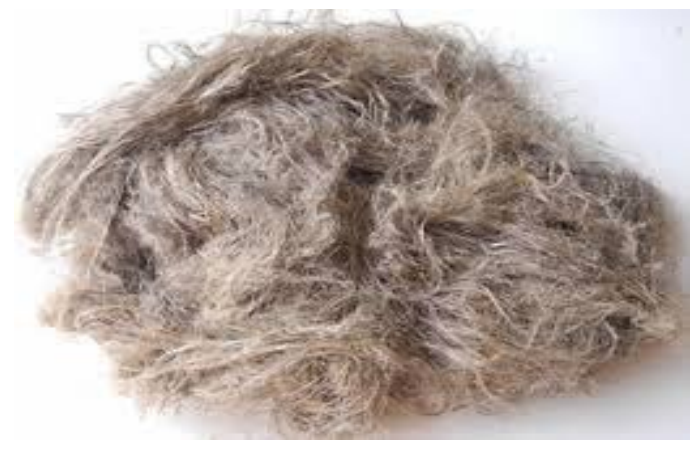

Fig.3 Flax Fibre [8]

Basalt fiber: It is a material made from extremely fine fibers of basalt, which is composed of the mineral's plagioclase, pyroxene, and olivine. It is like fiberglass, having better physicomechanical properties than fiberglass, but being significantly cheaper than carbon fiber. It is used as a fireproof textile in the aerospace and automotive industries and can also be used as a composite to produce products such as camera tripods. [9]

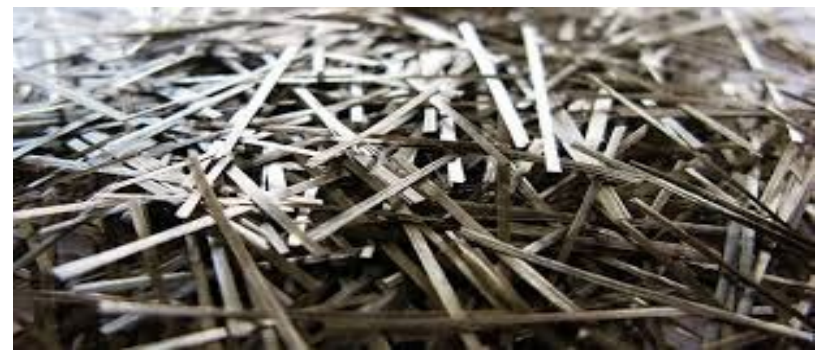

Fig.4 Basalt Fibre [9] 


\section{Carding}

Carding is a mechanical process that disentangles, cleans and intermixes fibres to produce a continuous web or silver suitable for subsequent processing. This is achieved by passing the fibres between differentially moving surfaces covered with card clothing. It breaks up locks and unorganised clumps of fibre and then aligns the individual fibres to be parallel with each other. In preparing wool fibre for spinning, carding is the step that comes after teasing. [10]

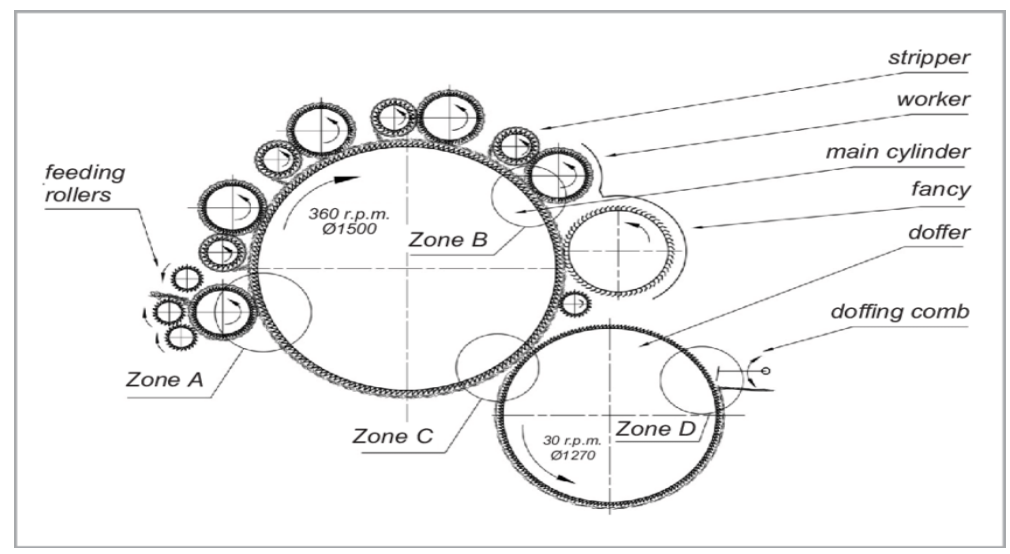

Fig.5 Carding Machine Schematic Diagram [10]

\section{Needle Punching}

Needle punching is a nonwoven process by which the fibres are mechanically entangled to produce a nonwoven fabric by repeated penetration of barbed needles through a preformed dry fibrous web. The needle board is mounted on a beam which is given an up and down reciprocating motion by means of an eccentric crank mechanism. As a result, the fibres are mechanically interlocked, thereby providing the mechanical strength. [11]

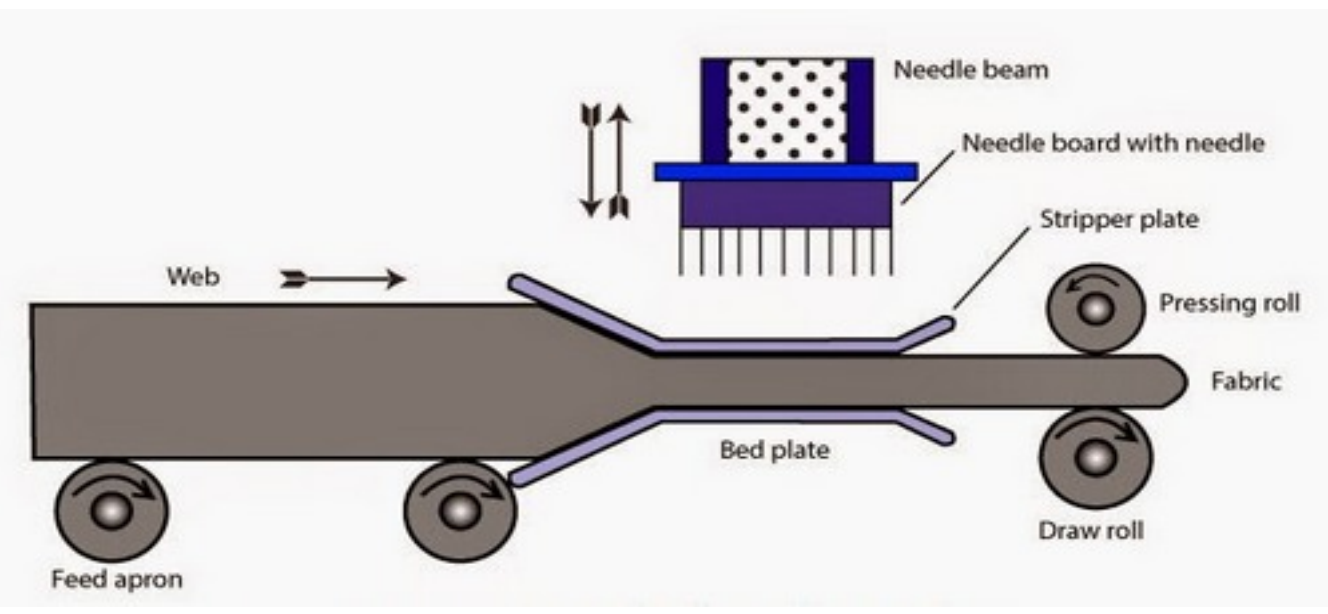

Fig.6 Needle Punching Process [11] 


\section{Sample Preparation:}

Sample 1 : Poly Propylene (Without Basalt)

Composition : $: 50 \% \mathrm{PP}+25 \%$ Kenaf $+25 \%$ Flax

Calculation $: 1400=\frac{?}{700 * 400} * 10^{\wedge} 6$

$$
?=392 \mathrm{~g} \text { (material needed) }
$$

$$
196 \mathrm{~g}(\mathrm{PP}) \quad 196 \mathrm{~g}(\mathrm{~K}+\mathrm{F})
$$

Approximated material required: 200 g PP +100 g Kenaf +100 g Flax

Table 1: Sequence of Carding

\begin{tabular}{|c|c|c|c|}
\hline No. of Carding & Start $(\mathrm{g})$ & Mass $(\mathrm{g})$ & Loss $(\mathrm{g})$ \\
\hline 1 & 400 & 360 & 30 \\
\hline 2 & 180 & 150 & 25 (Discarded) \\
\hline 3 & 150 & 135 & 20 (Discarded) \\
\hline 4 & 70 & 50 & 10 (Discarded) \\
\hline 5 & $80(40 \mathrm{PP}+40 \mathrm{KF})$ & 70 & 10 \\
\hline
\end{tabular}

The total collected material (405 g) is separated into two samples $(195 \mathrm{~g}+210 \mathrm{~g})$ and further underwent needle punching process.

\section{Procedure:}

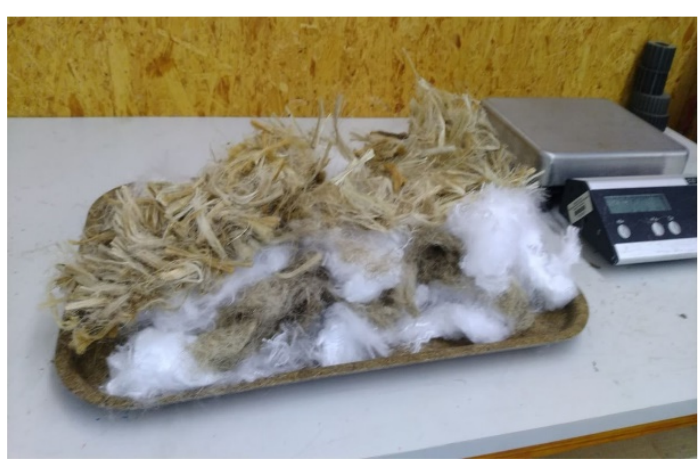

Fig.7 Arrangement of PP, Kenaf \& Flax

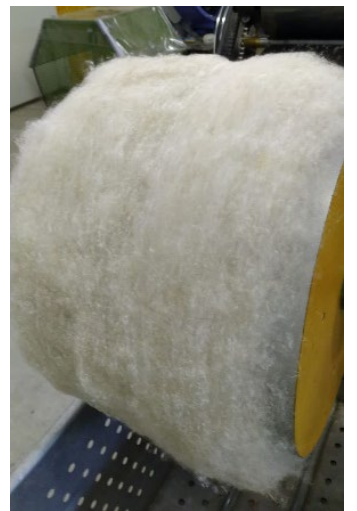

Fig.8 Material after needling 

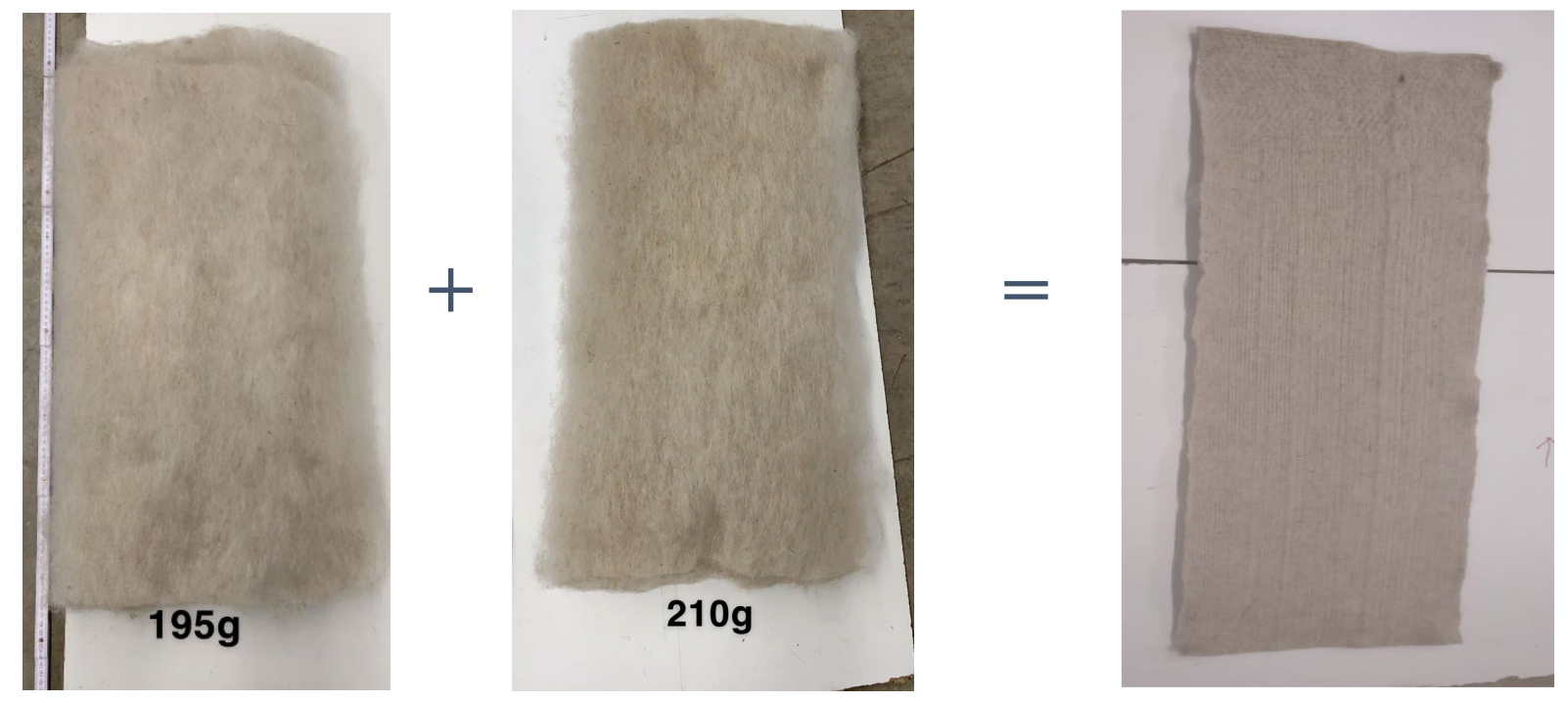

Fig.9 700mm*35mm Fibre samples for needling

Fig.10 Material after needling

Observation: During the carding process it was agglomerated when compared to polypropylene fibre and even the quality of fleece was not as good as PP fibre.

Sample 2 : Poly Propylene (with Basalt)

Composition : $50 \% \mathrm{PP}+25 \%$ Kenaf - Flax $+25 \%$ Basalt (D.B.F)

Calculation $\quad: 1400=\frac{?}{700 * 400} * 10^{\wedge} 6$

$?=392 \mathrm{~g}$ (material needed)

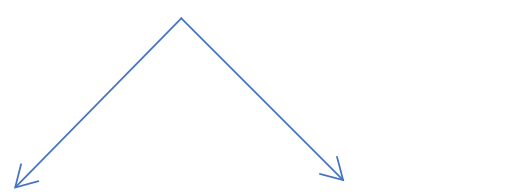

$$
196 \mathrm{~g}(\mathrm{PP}) \quad 98 \mathrm{~g}(\mathrm{~K}+\mathrm{F})+98 \mathrm{~g} \text { (Basalt) }
$$

Approximated material required: $200 \mathrm{~g}$ PP $+100 \mathrm{~g}($ Kenaf + Flax $)+100 \mathrm{~g}$ Basalt

Table 2: Sequence of Carding

\begin{tabular}{|c|c|c|c|}
\hline No. of Carding & Start $(\mathrm{g})$ & Mass $(\mathrm{g})$ & Loss $(\mathrm{g})$ \\
\hline 1 & 400 & 365 & 25 \\
\hline 2 & 135 & 120 & 15 (Discarded) \\
\hline 3 & 240 & 190 & 30 (Discarded) \\
\hline
\end{tabular}

Material Addition:

Composition : $60 \mathrm{~g}$ PP +30 g Kenaf - Flax +30 Basalt (D.B.F)

Table 3: Sequence of Carding

\begin{tabular}{|c|c|c|c|}
\hline No. of Carding & Start $(\mathrm{g})$ & Mass $(\mathrm{g})$ & Loss $(\mathrm{g})$ \\
\hline 1 & 120 & 110 & 10 \\
\hline 2 & 120 & 95 & 10 (Discarded) \\
\hline
\end{tabular}




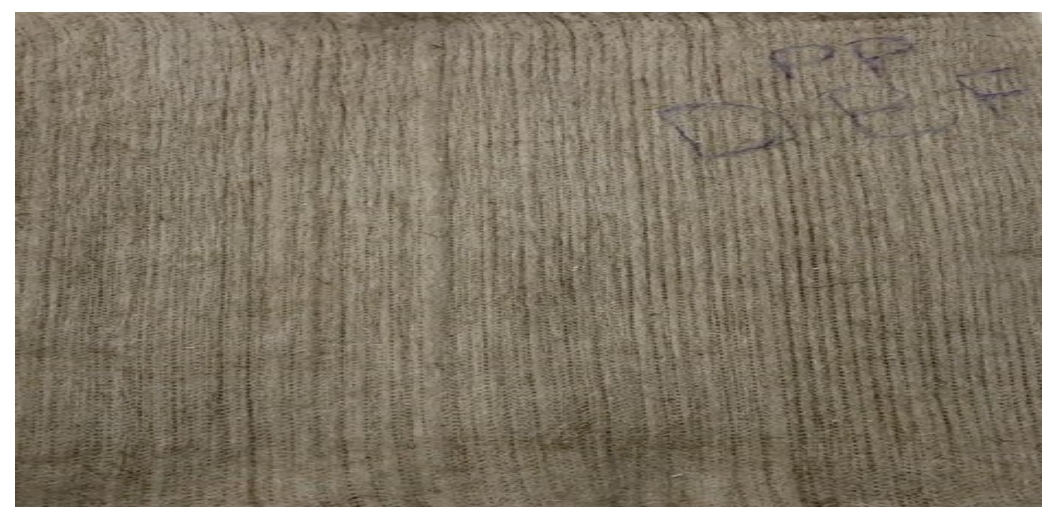

Fig.11 Final Sample of Poly Propylene with Basalt (D.B.F)

Sample 3 : Poly Propylene (with Basalt)

Composition $\quad: 260 \mathrm{~g}$ PP $+130 \mathrm{~g}($ Kenaf + Flax $)+130 \mathrm{~g}$ Basalt (F.T)

Table 4: Sequence of Carding

\begin{tabular}{|c|c|c|c|}
\hline No. of Carding & Start $(\mathrm{g})$ & Mass $(\mathrm{g})$ & Loss $(\mathrm{g})$ \\
\hline 1 & 520 & 495 & 15 \\
\hline 2 & 200 & 185 & 25 (Discarded) \\
\hline 3 & 245 & 215 & 20 (Discarded) \\
\hline
\end{tabular}

Final Sample Length - 305g

Length- $60 \mathrm{~cm}$

Width- $36 \mathrm{~cm}$

$\mathrm{Aw}=305 /(60 * 36)=1412 \mathrm{~g} / \mathrm{m}^{\wedge} 2$

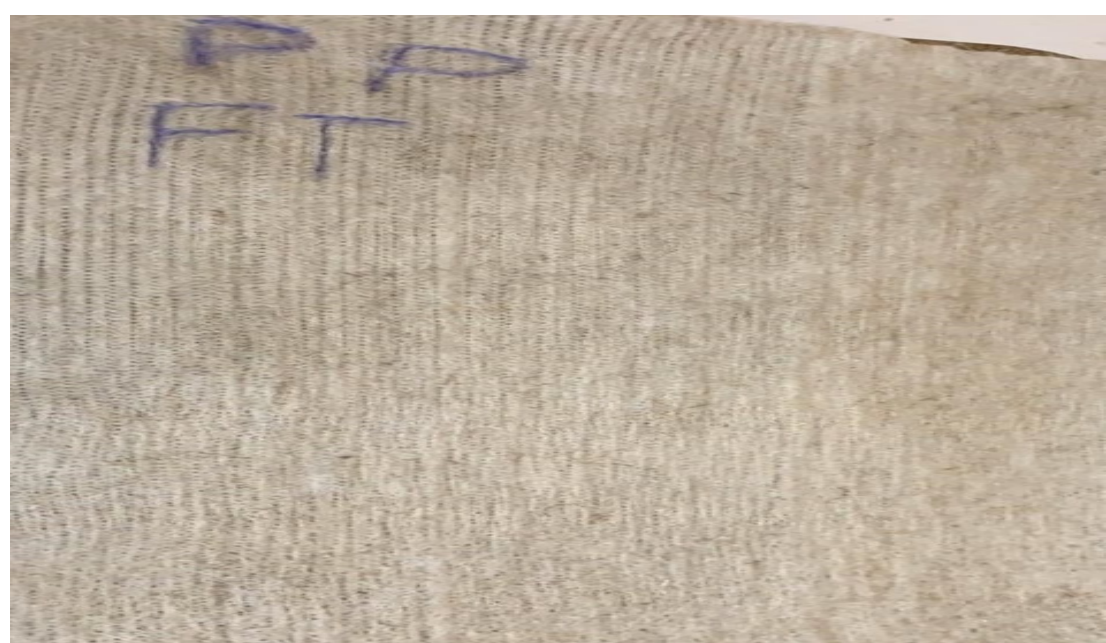

Fig.12 Final Sample of Poly Propylene with Basalt (F.T) 


\section{Observation:}

As seen in the Figure.13 during the Carding process of Basalt (D.B.F), Basalt fibres are been stuck onto the rollers due to which we have lot of wastage in this type of Basalt (D.B.F) compared to Basalt (F.T).

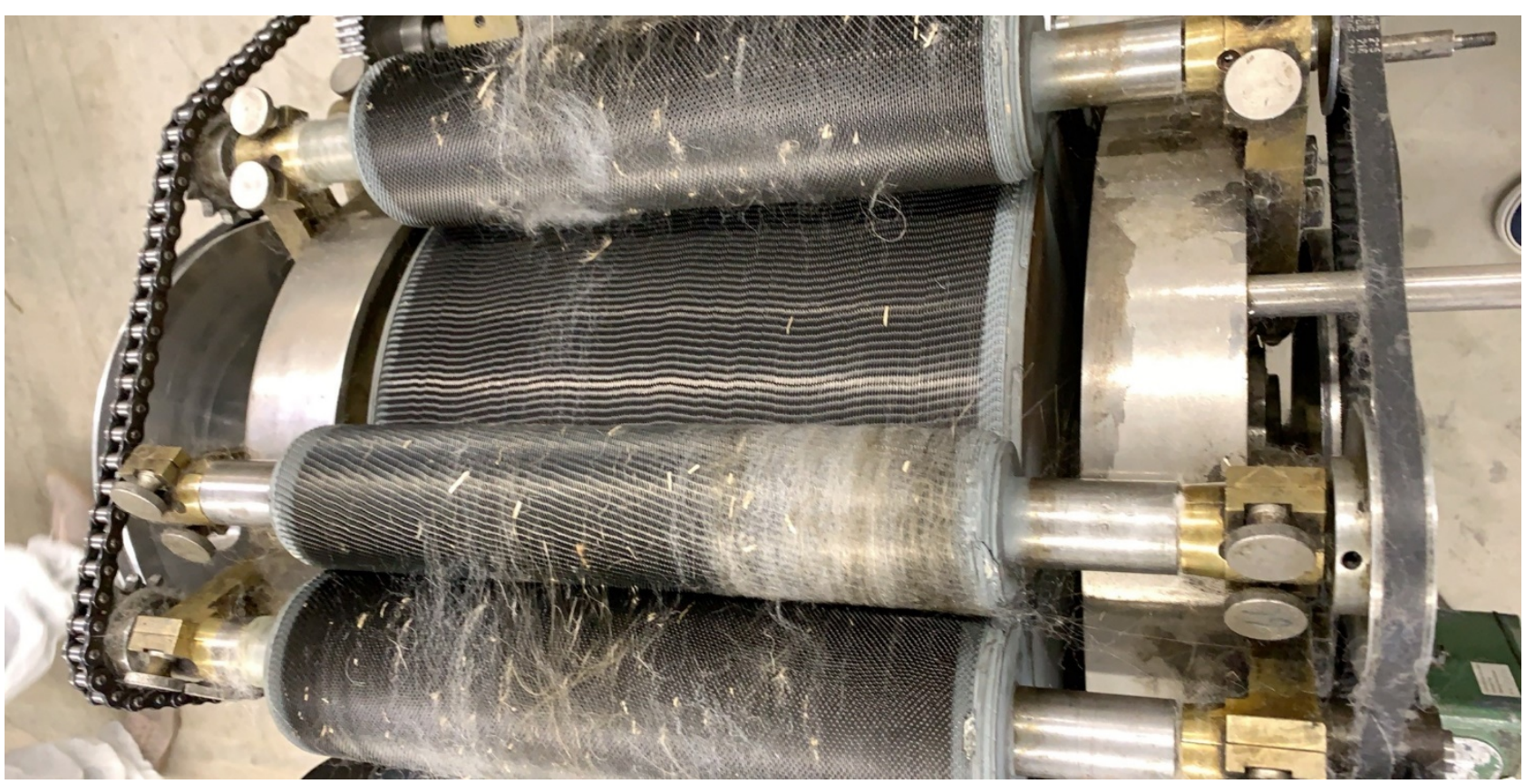

Fig.13 Carding process of Basalt (D.B.F)

$>$ By comparing the amount of starting material taken for different samples and the loss it has generated during carding it has resulted to an average of $17 \%$ for the Initial carding.

\begin{tabular}{|c|c|c|}
\hline Start Mass $(\mathrm{g})$ & Loss $(\mathrm{g})$ & Percentage Loss (\%) \\
\hline 400 & 25 & 16 \\
\hline 120 & 10 & 12 \\
\hline 520 & 15 & 34.6 \\
\hline 80 & 10 & 8 \\
\hline \multicolumn{2}{|c|}{ Average (\%) } \\
\hline
\end{tabular}

Table.5 Comparison of Percentage Loss of Fibre for Initial Carding

$>$ Coming to the second carding the amount of loss generated during carding is $7.9 \%$

\begin{tabular}{|c|c|c|}
\hline Start Mass(g) & Loss $(\mathrm{g})$ & Percentage Loss (\%) \\
\hline 200 & 25 & 8 \\
\hline 150 & 20 & 7.5 \\
\hline 240 & 30 & 8 \\
\hline 135 & 15 & 9 \\
\hline 70 & 10 & 7 \\
\hline \multicolumn{2}{|c|}{ Average (\%) } \\
\hline
\end{tabular}

Table.6 Comparison of Percentage Loss of Fibre for Second Carding 


\section{Press Molding:}

Compression Moulding is a method of moulding in which the moulding material, generally preheated, is first placed in an open, heated mould cavity. The mould is closed with a top force or plug member, pressure is applied to force the material into contact with all mould areas, while heat and pressure are maintained until the moulding material has cured. The process employs thermosetting resins in a partially cured stage, either in the form of granules, puttylike masses, or preforms. [12]

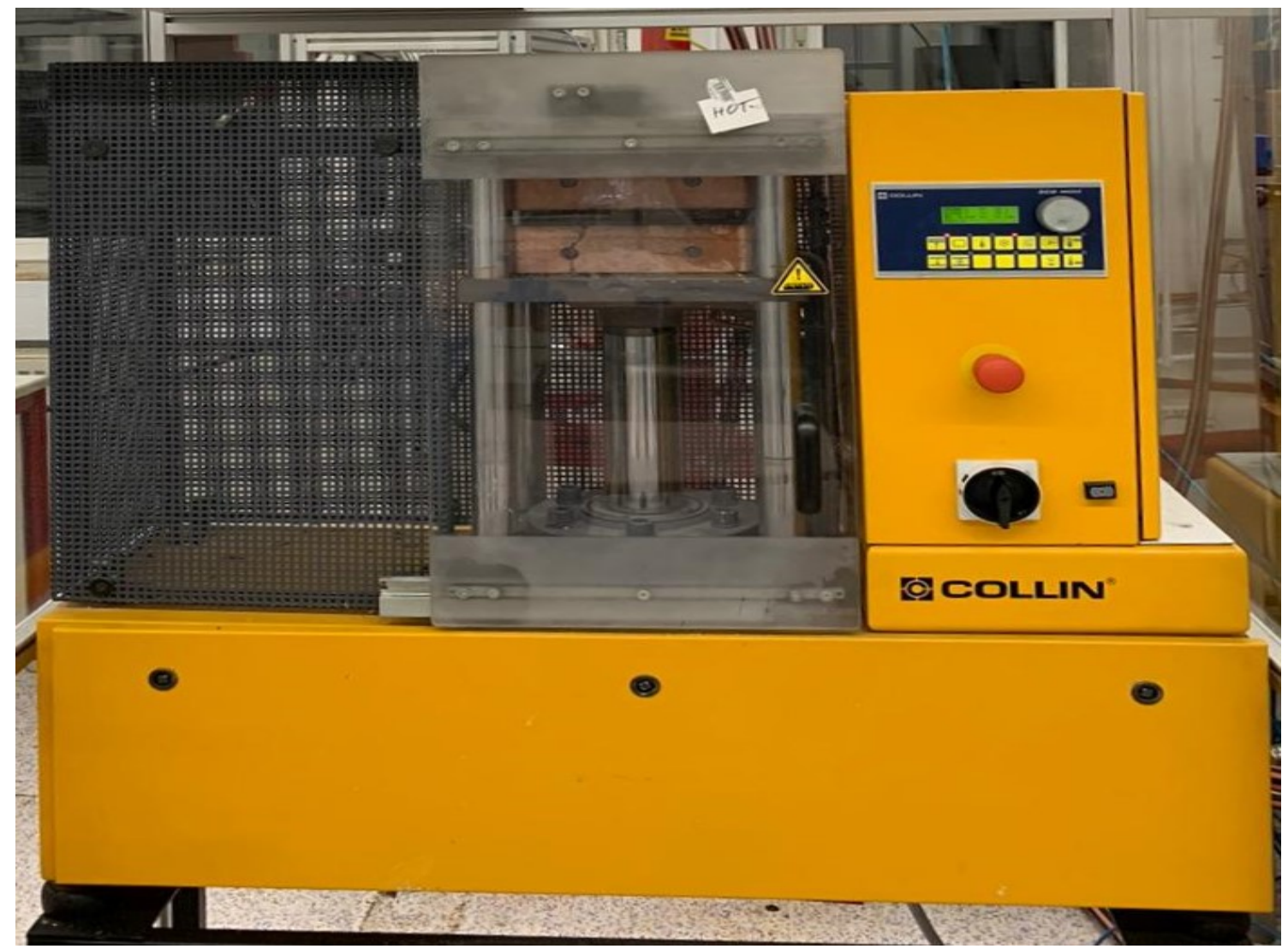

Fig.14 Press Molding Machine

In this Process we have three different phases which differ mainly in terms of Temperature, Pressure and Time. In the Initial phase we can only control the Pressure, where as the Temperature can be varied in the next Phases.

\begin{tabular}{|c|c|c|c|}
\hline Phase & Temperature & Pressure & Time \\
\hline Phase- 1 & $200^{\circ} \mathrm{c}$ & $50 \mathrm{bar}$ & $60 \mathrm{sec}$ \\
\hline Phase- 2 & $60^{\circ} \mathrm{c}$ & $50 \mathrm{bar}$ & $80 \mathrm{sec}$ \\
\hline Phase-3 & $60^{\circ} \mathrm{c}$ & $50 \mathrm{bar}$ & $300 \mathrm{sec}$ \\
\hline
\end{tabular}

Table.7 Parameters given to the Press Mold for Each Phase 


\section{Compression Molded Samples of PP + KF (without Basalt):}

After the carding process the samples are cut into the dimensions according to the Mold, the specimens are undergone for three phases in the Press Mold and after the process it is cooled to the room temperature and then they are cut into specimens to carry out Mechanical Tests (Tensile and Charpy).

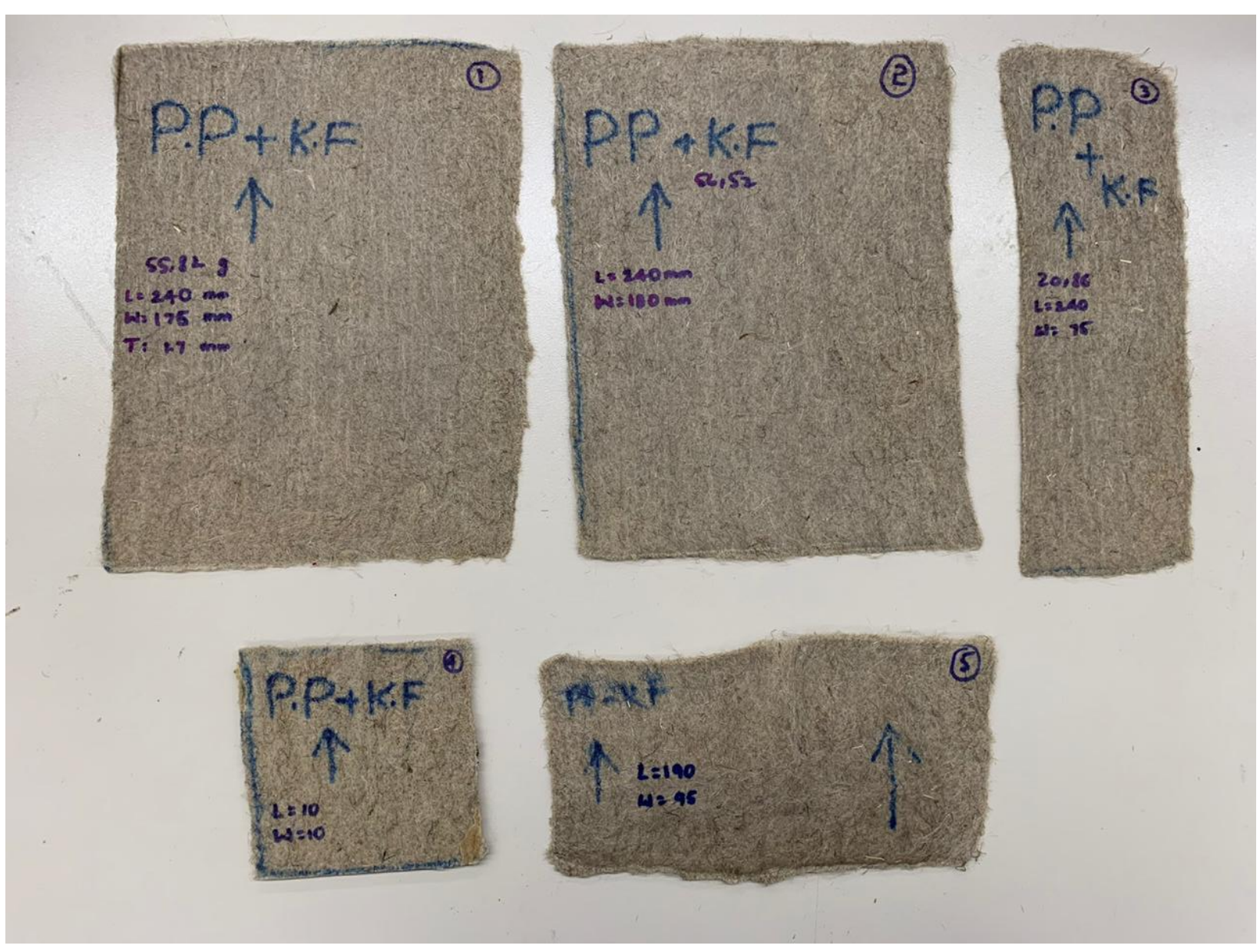

Fig. 15 Press Molded Samples of PP + KF

\begin{tabular}{|c|c|c|c|}
\hline Plate N.o. & Length & Width & Thickness \\
\hline 1. & $240 \mathrm{~mm}$ & $175 \mathrm{~mm}$ & $1.7 \mathrm{~mm}$ \\
\hline 2. & $240 \mathrm{~mm}$ & $180 \mathrm{~mm}$ & $1.7 \mathrm{~mm}$ \\
\hline 3. & $240 \mathrm{~mm}$ & $75 \mathrm{~mm}$ & $1.7 \mathrm{~mm}$ \\
\hline 4. & $100 \mathrm{~mm}$ & $100 \mathrm{~mm}$ & $4.0 \mathrm{~mm}$ \\
\hline 5. & $190 \mathrm{~mm}$ & $95 \mathrm{~mm}$ & $1.7 \mathrm{~mm}$ \\
\hline
\end{tabular}

Table.8 Press Molded Sample Dimensions of PP + KF (without Basalt) 


\section{Compression Molded Samples of PP + DBF (with Basalt):}

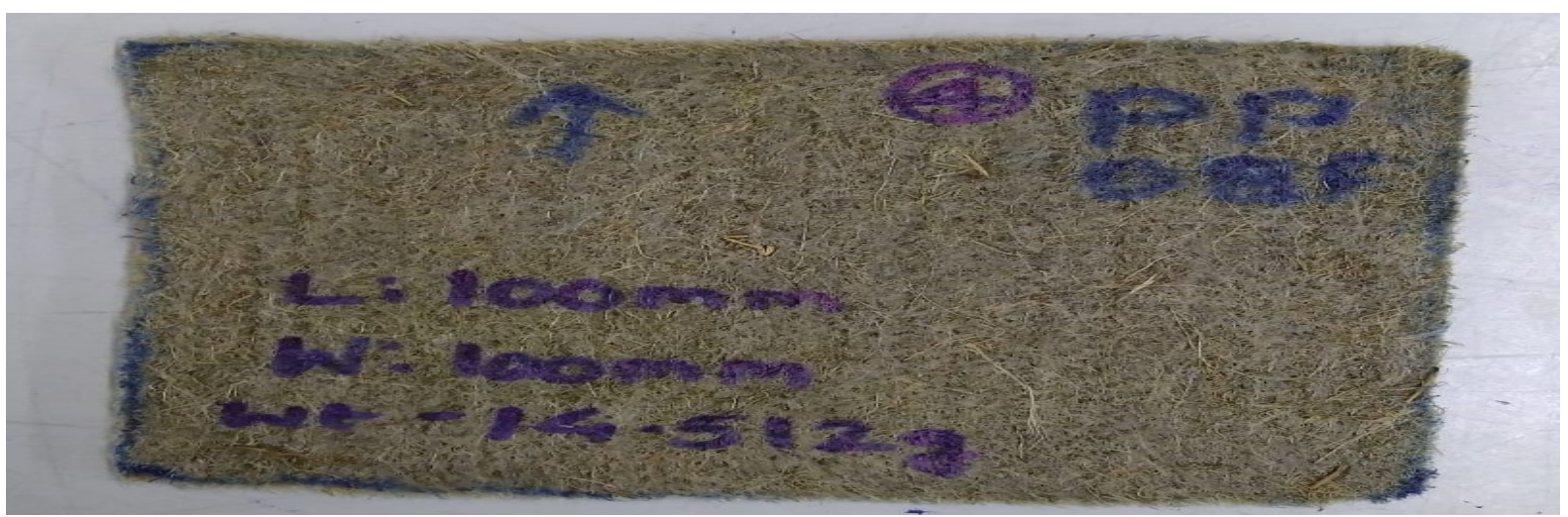

Fig.16 Press Molded Samples of PP + DBF

\begin{tabular}{|c|c|c|c|}
\hline Plate N.o. & Length & Width & Thickness \\
\hline 1. & $210 \mathrm{~mm}$ & $175 \mathrm{~mm}$ & $1.7 \mathrm{~mm}$ \\
\hline 2. & $250 \mathrm{~mm}$ & $190 \mathrm{~mm}$ & $1.7 \mathrm{~mm}$ \\
\hline 3. & $220 \mathrm{~mm}$ & $90 \mathrm{~mm}$ & $1.7 \mathrm{~mm}$ \\
\hline 4. & $100 \mathrm{~mm}$ & $100 \mathrm{~mm}$ & $4.0 \mathrm{~mm}$ \\
\hline
\end{tabular}

Table.9 Samples Dimension of PP + DBF (with Basalt)

\section{Compression Molded Samples of PP + FT (with Basalt):}

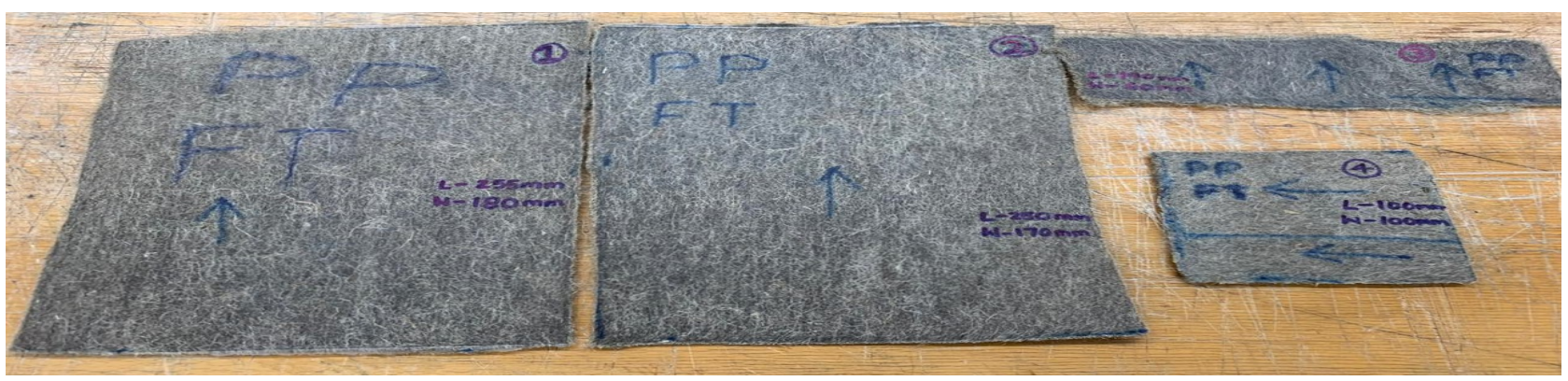

Fig. 17 Press Molded Samples of PP + FT

\begin{tabular}{|c|c|c|c|}
\hline Plate N.o. & Length & Width & Thickness \\
\hline 1. & $255 \mathrm{~mm}$ & $180 \mathrm{~mm}$ & $1.7 \mathrm{~mm}$ \\
\hline 2. & $250 \mathrm{~mm}$ & $170 \mathrm{~mm}$ & $1.7 \mathrm{~mm}$ \\
\hline 3. & $190 \mathrm{~mm}$ & $60 \mathrm{~mm}$ & $1.7 \mathrm{~mm}$ \\
\hline 4. & $100 \mathrm{~mm}$ & $100 \mathrm{~mm}$ & $4.0 \mathrm{~mm}$ \\
\hline
\end{tabular}

Table.10 Samples Dimension of PP + FT (with Basalt) 


\section{MECHANICAL TESTS}

\section{Experimental Setup:}

Following tests were conducted in the present work,

Tensile Test

Impact Test (Charpy)

The tests were conducted using a calibrated Universal Testing Machine (UTM). Different tests were conducted, such as the Tensile test and Impact test carried (Charpy type) on Impact machine.

\section{TENSILE TEST:}

One of the most fundamental mechanical tests that can be performed on a material is the tensile test. Tensile properties indicate how the material will react to forces being applied in tension. A tensile test is a fundamental mechanical test where a carefully prepared specimen is loaded in a very controlled manner while measuring the applied load the and the elongation of the specimen over some distance. These tests are used to determine the modulus of elasticity, elastic limit, elongation, proportional limit, reduction in area, tensile strength, yield point, yield strength, and other tensile properties. [13]

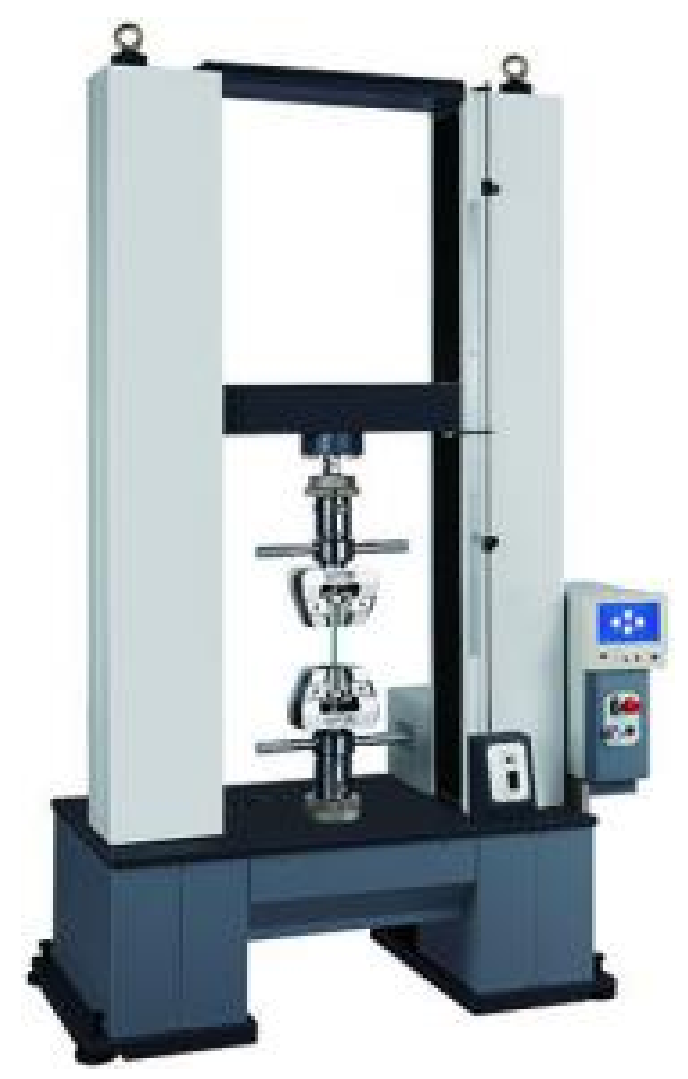

Fig.18 Tensile Testing Machine [13] 


\section{Procedure:}

$>$ The specimens were chosen, care is to be taken to ensure that the specimens did not have any notching or cracks from manufacturing or any surface defects that would adversely affect the tensile tests.

$>$ Before loading the specimens in the Tensile machine, the computer system connected to the machine was set up by inputting the necessary information of gauge length and width of the specimen. The computer system was then prepared to record data and output necessary load-deflection graphs.

$>$ The specimens were loaded into the Instron machine, and a tensile test was performed. The data was recorded electronically in text files shown in Appendix B and the loaddeflection curve was shown on the computer screen as a visual representation. Fig.18 gives a visual representation of the apparatus and the set-up used for testing.

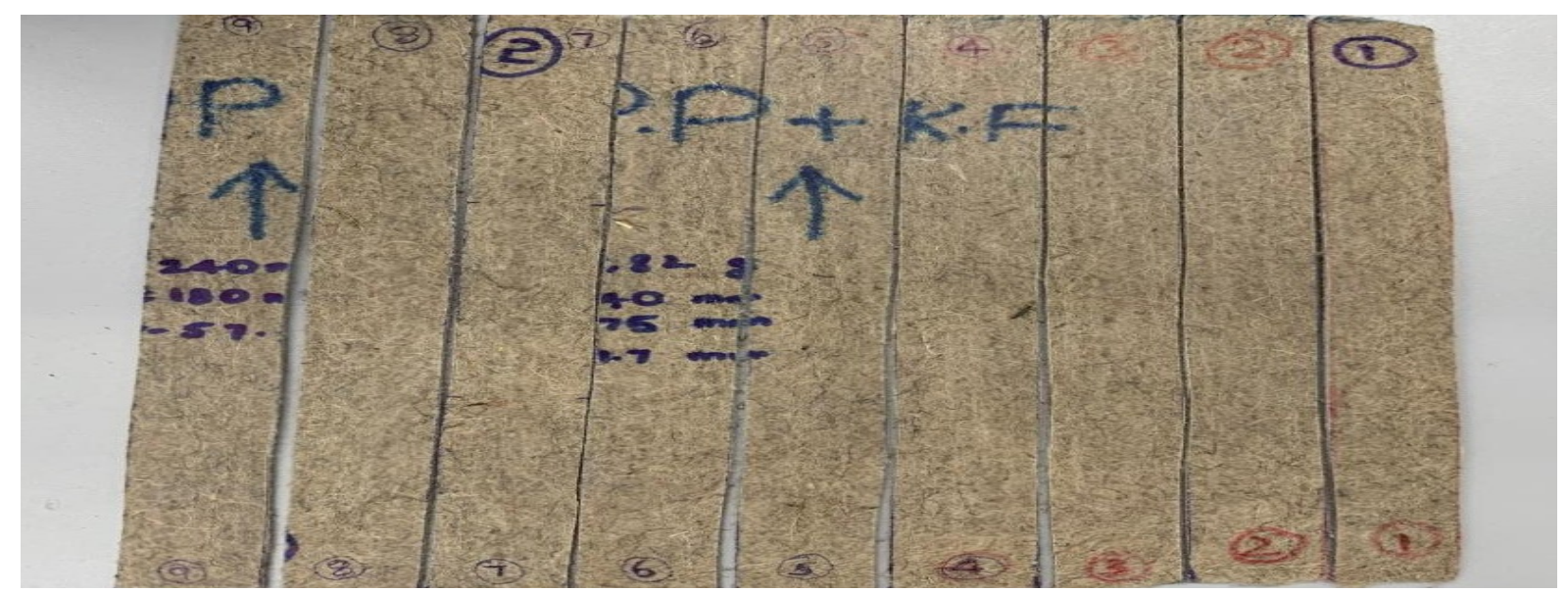

Fig.19 Sample of $\mathbf{P P}+\mathbf{K} . \mathbf{F}$ before Tensile Test

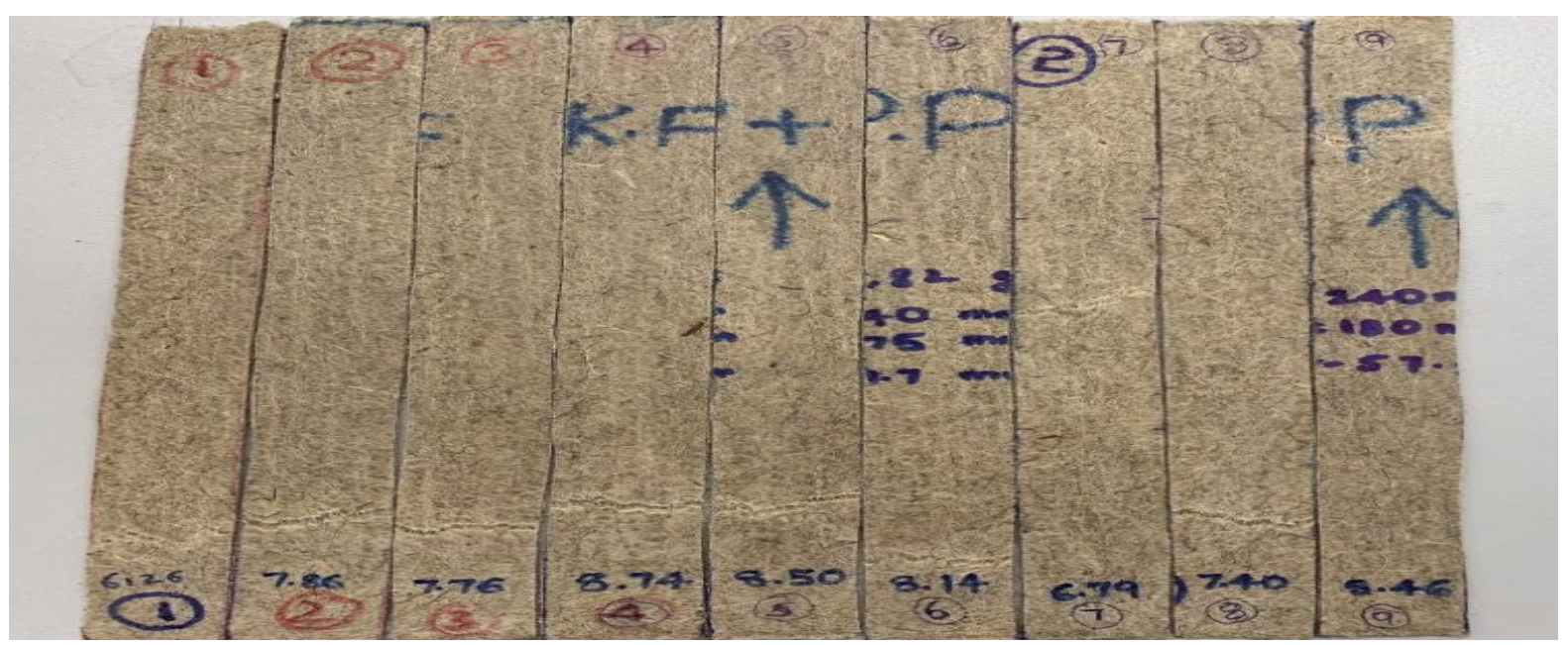

Fig.20 Sample of $\mathbf{P P}+\mathbf{K} . \mathbf{F}$ After Tensile Test 


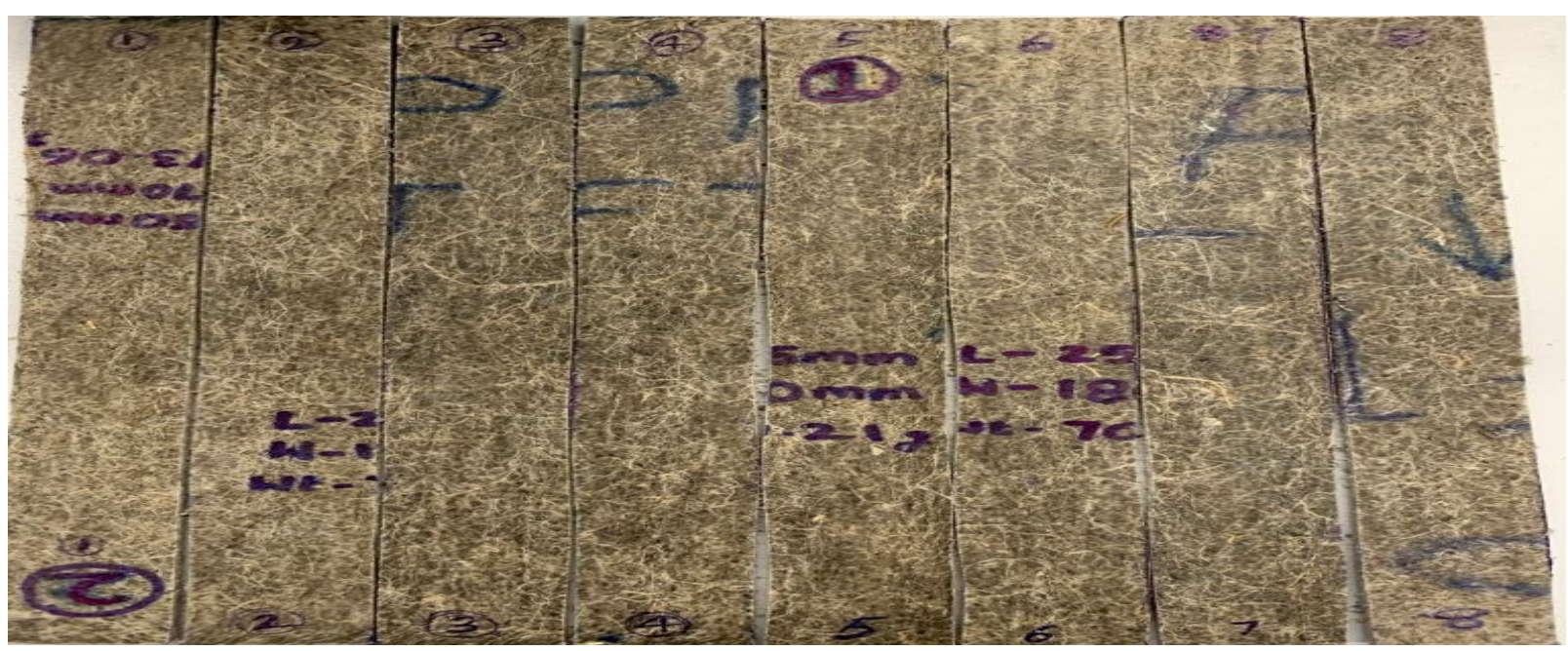

Fig.21 Sample of PP + D.B.F Before Tensile Test

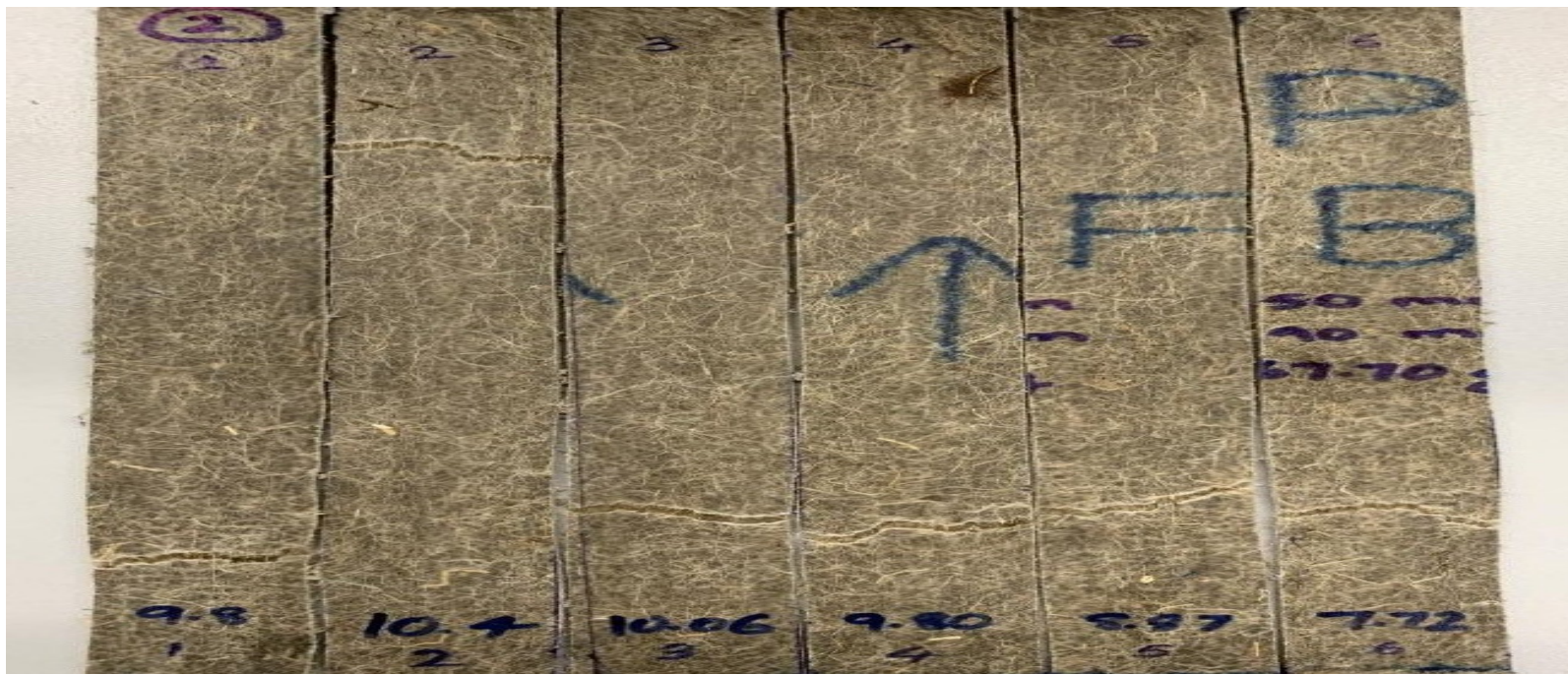

Fig.22 Sample of PP + D.B.F After Tensile Test

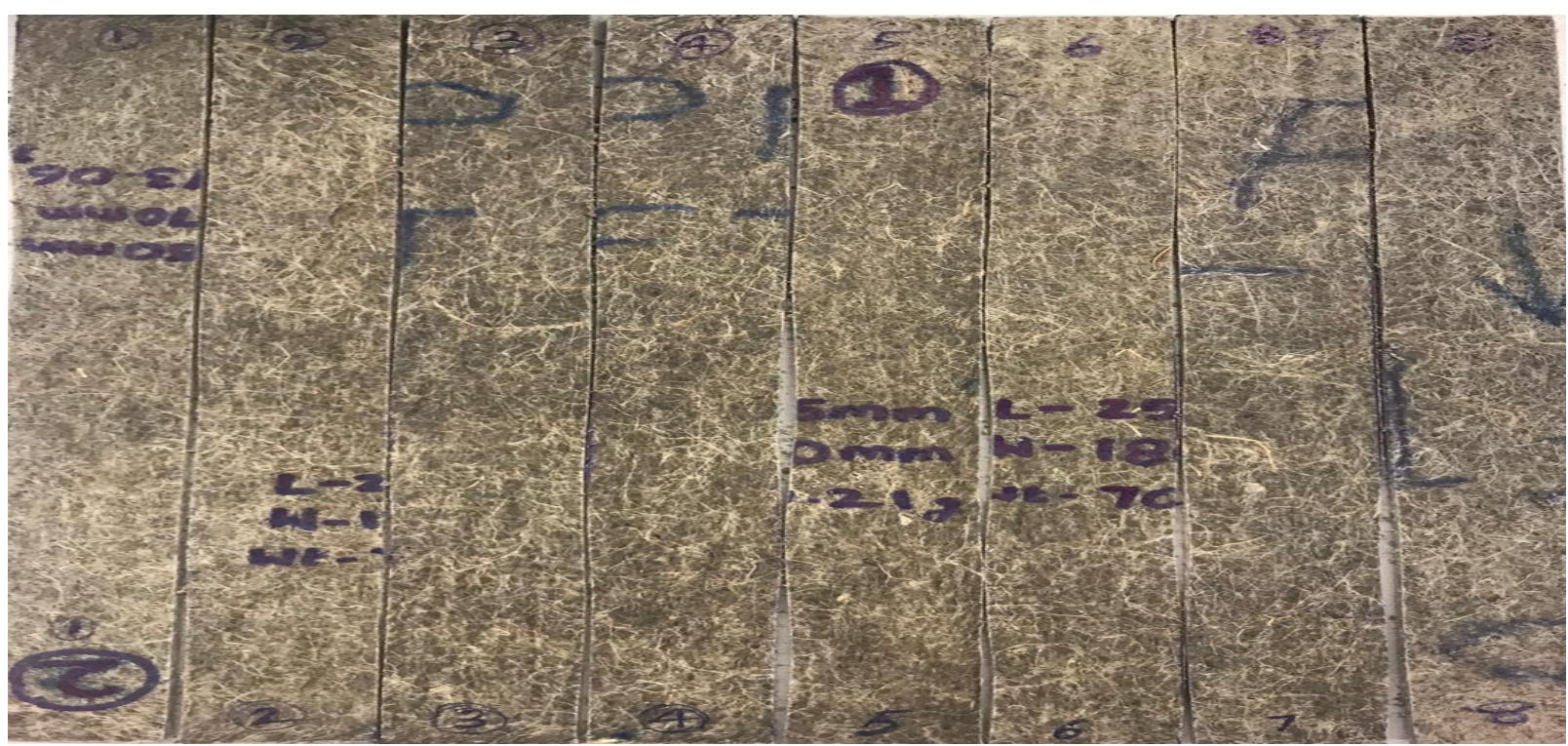

Fig.23 Sample of PP + F.T Before Tensile Test 


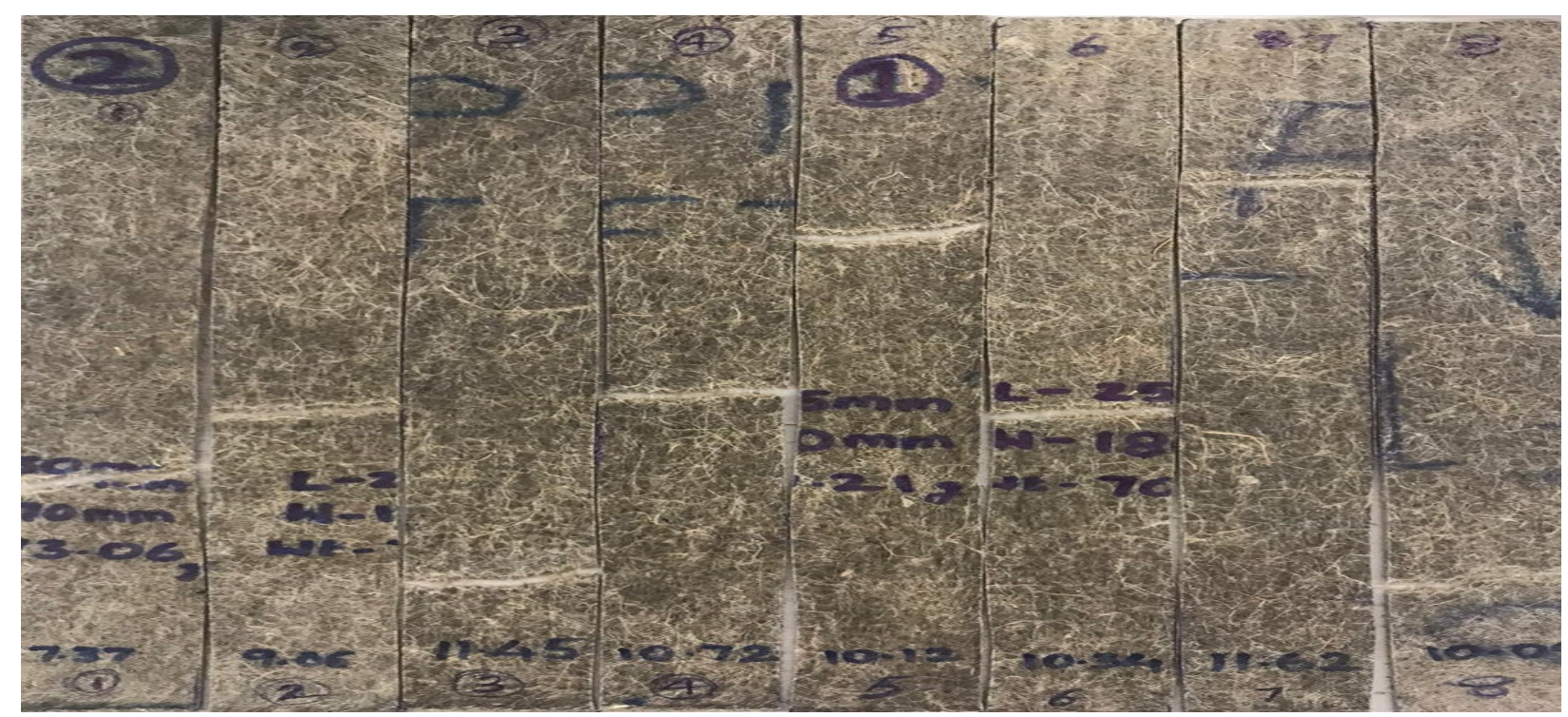

Fig.24 Sample of PP + F.T After Tensile Test

\section{CHARPY IMPACT TEST:}

The Charpy test is measured by allowing a pendulum to strike a grooved machined test piece and measuring the energy absorbed in the break. The Charpy test measures the energy absorbed by a standard notched specimen while breaking under an impact load. This test continues to be used as an economical quality control method to determine the notch sensitivity and impact toughness of engineering materials. The Charpy test was is commonly used on metals, but it also applied to composites, ceramics, and polymers. It is one of the most commonly evaluates the relative toughness of a material. This test consists of striking a suitable specimen with a hammer on a pendulum arm while the specimen is held securely at each end. The hammer strikes opposite the notch. The energy absorbed by the specimen is determined by precisely measuring in the motion of the pendulum arm. Important factors that affect the toughness of a material include low temperature, high strain rates (by impact or pressurization), and stress concentrators such as notches, cracks, and voids.

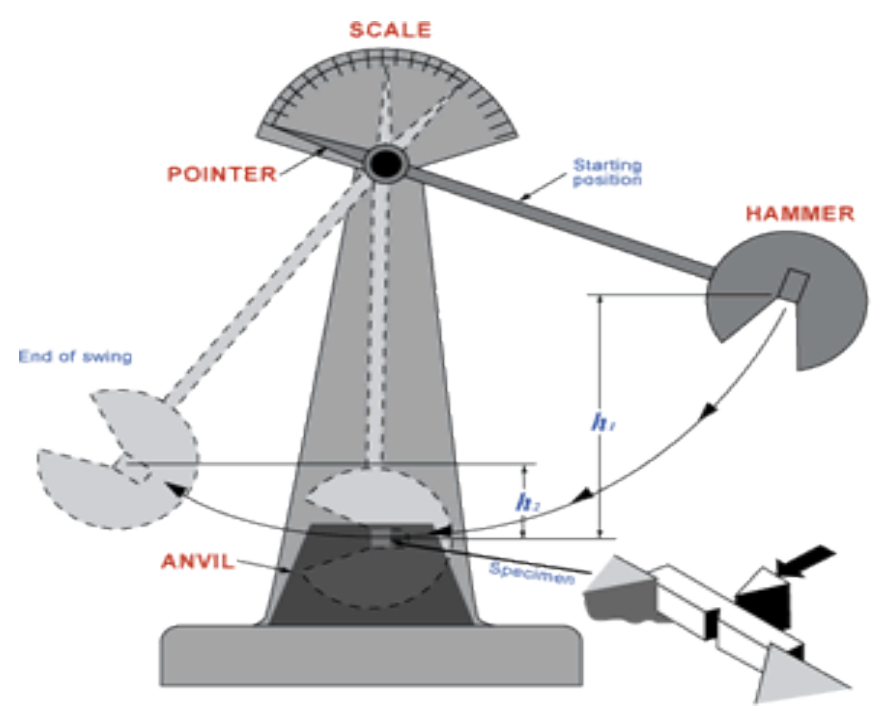

Fig.25 Charpy Testing Machine [14] 


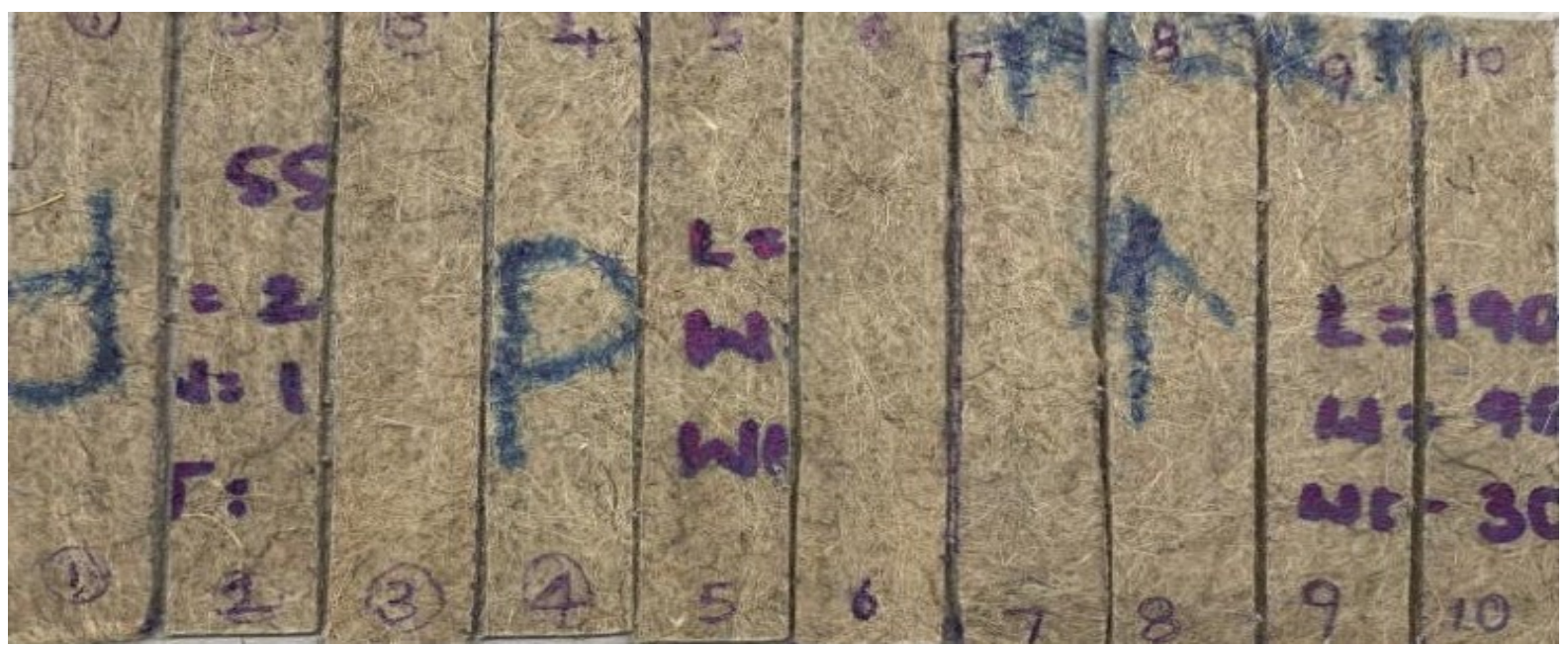

Fig.26 Sample of PP + K.F before Impact Test

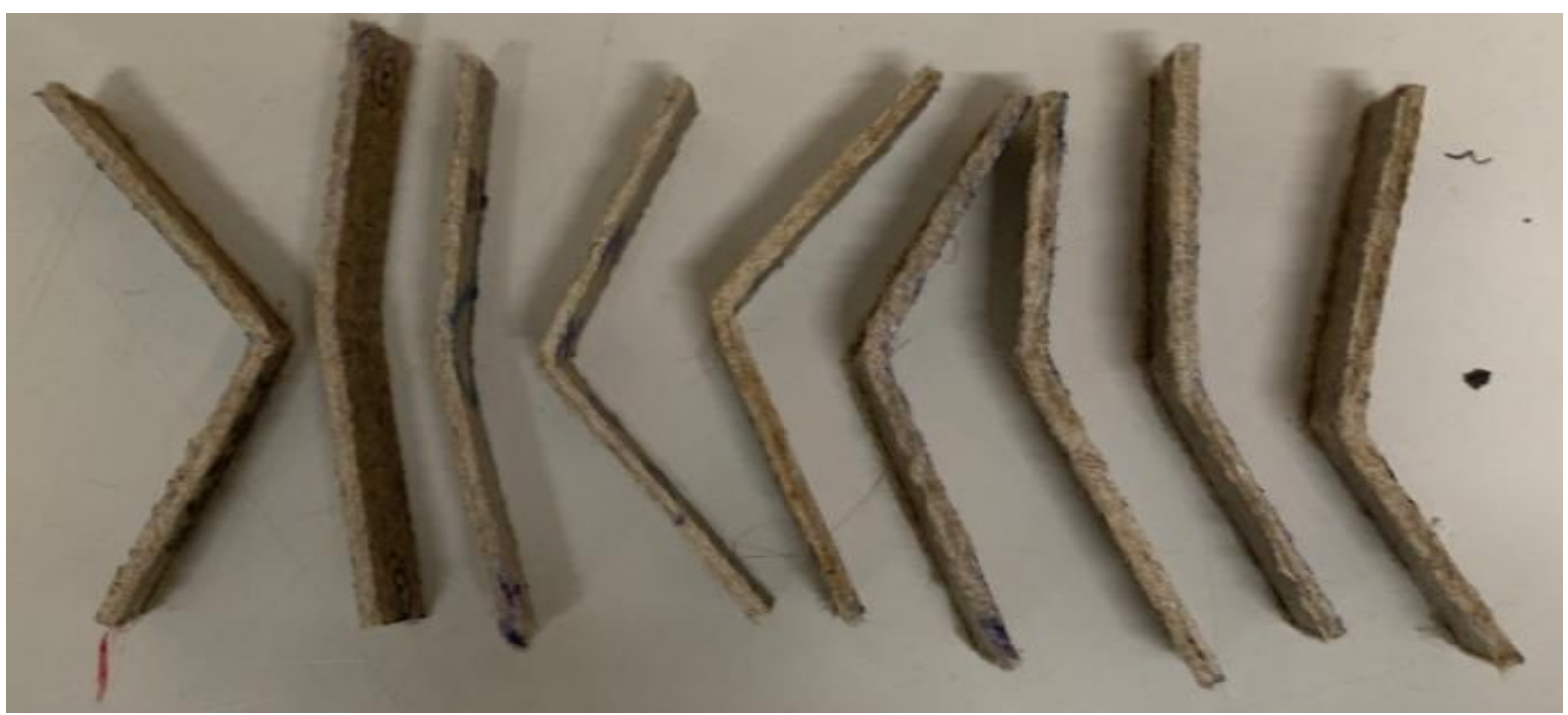

Fig.27 Sample of PP + K.F After Impact Test

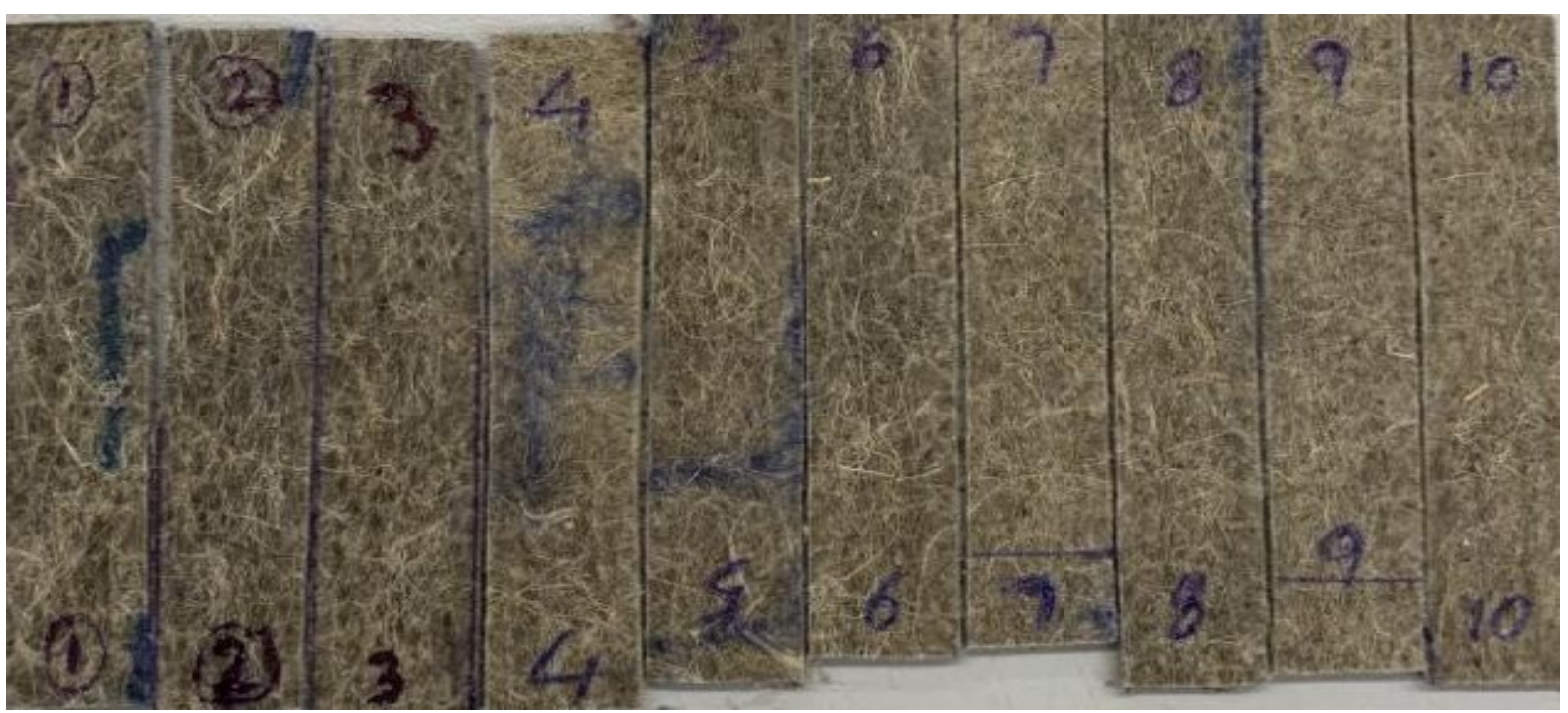

Fig.28 Sample of PP + D.B.F Before Impact Test 


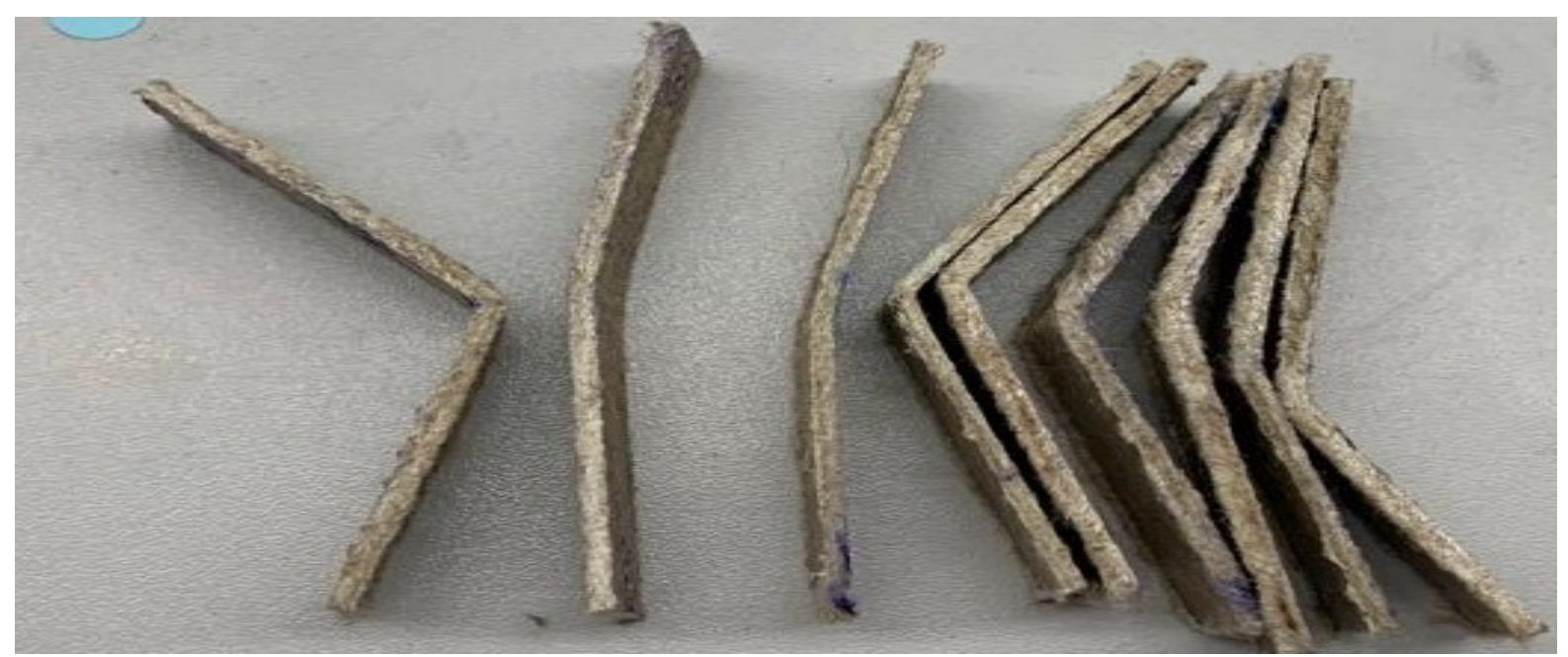

Fig.29 Sample of PP + D.B.F Before Impact Test

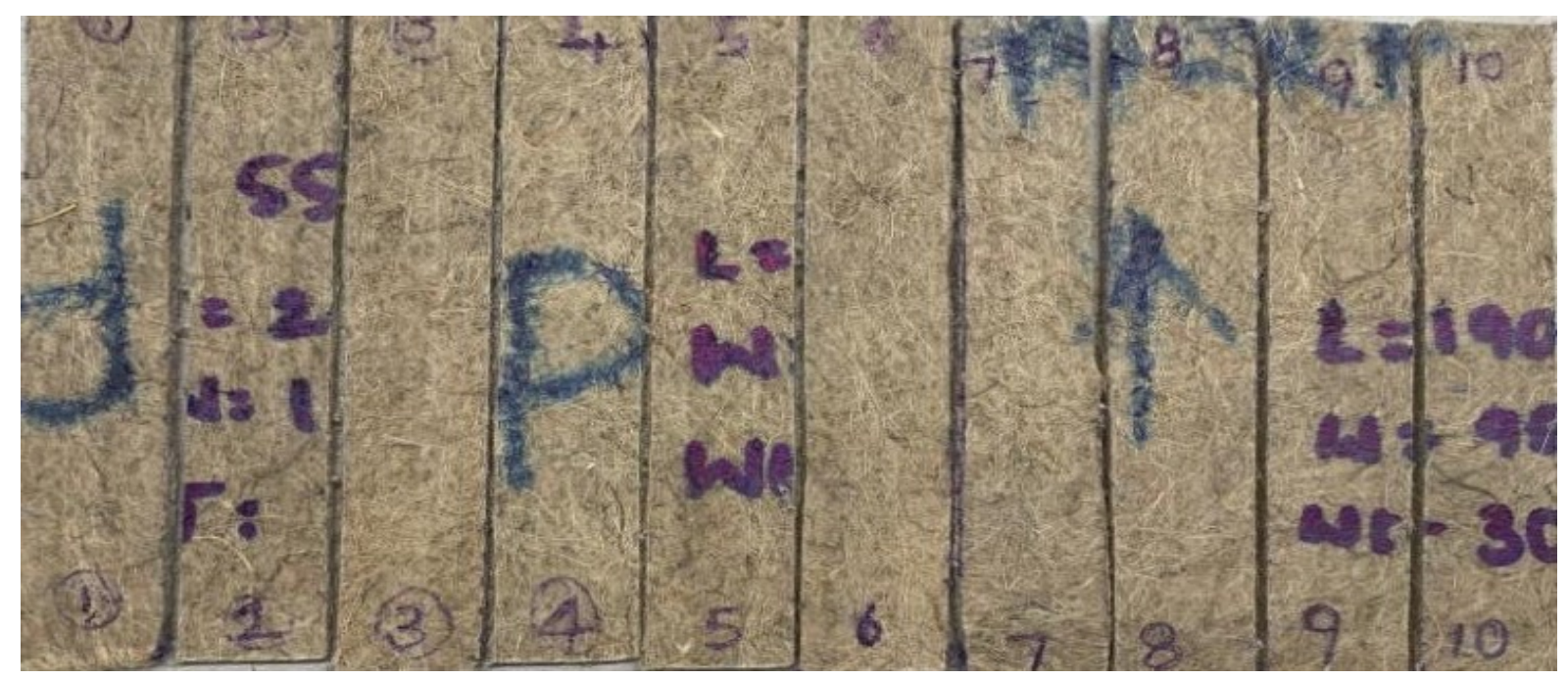

Fig.30 Sample of PP + F.T Before Impact Test

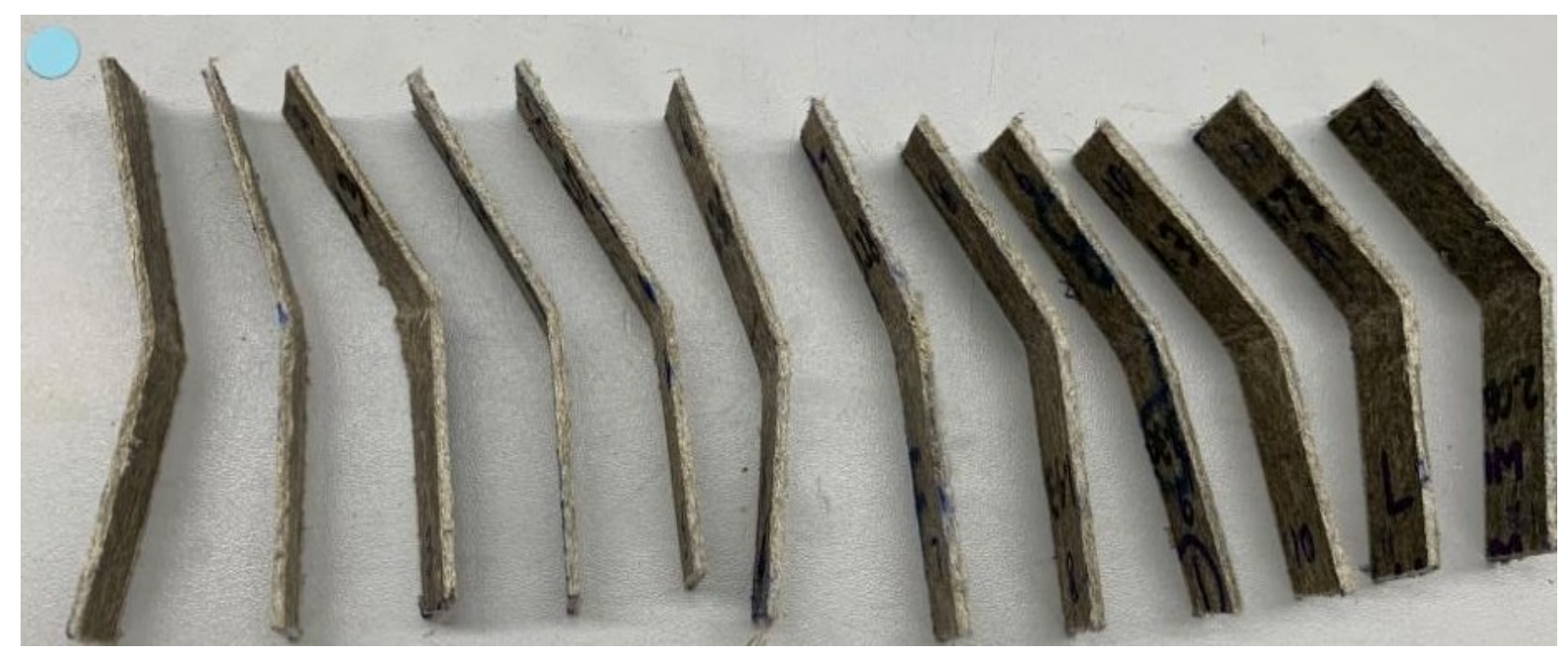

Fig.31 Sample of PP + F.T After Impact Test 


\section{Results and Discussions}

After conducting the tests, the results have been tabulated and compared with other samples. Even the Stress-Strain curves are also extracted form the results.

\section{TENSILE TEST:}

Sample 1 : Poly Propylene (PP + K.F)

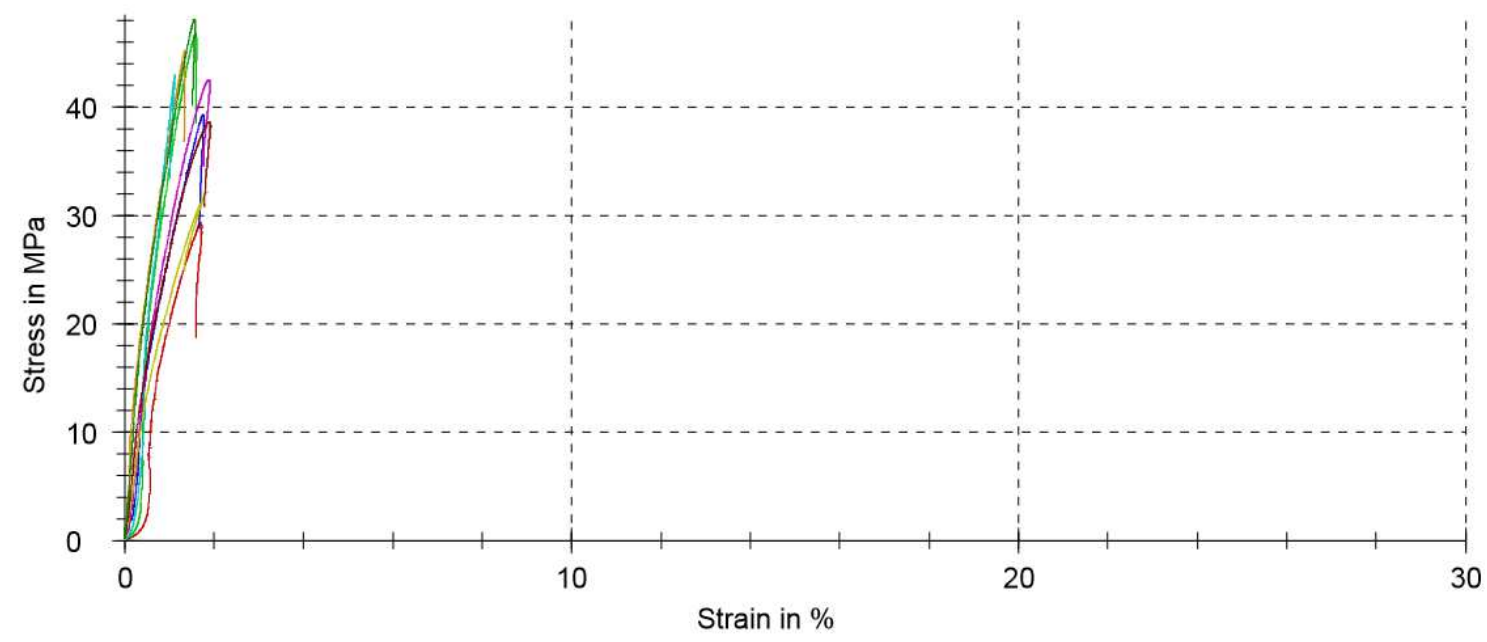

Fig.32 Stress-Strain graph of PP + K.F samples

\begin{tabular}{|c|c|c|c|}
\hline Specimen No. & $\sigma$ low (MPa) & $\sigma$ High (MPa) & Et (MPa) \\
\hline 1. & 0.102 & 0.523 & 203.87 \\
\hline 2. & 0.168 & 1.071 & 440.02 \\
\hline 3. & 0.587 & 4.340 & 1728.39 \\
\hline 4. & 1.955 & 14.82 & 6985.66 \\
\hline 5. & 0.594 & 6.302 & 3177.59 \\
\hline 6. & 0.247 & 2.726 & 1286.13 \\
\hline 7. & 0.944 & 6.891 & 3072.81 \\
\hline 8. & 1.405 & 9.395 & 4029.71 \\
\hline 9. & 1.763 & 13.27 & 5922.94 \\
\hline
\end{tabular}

Table.11 Experimental values of $\mathbf{P P}+\mathbf{K} . \mathbf{F}$ samples 


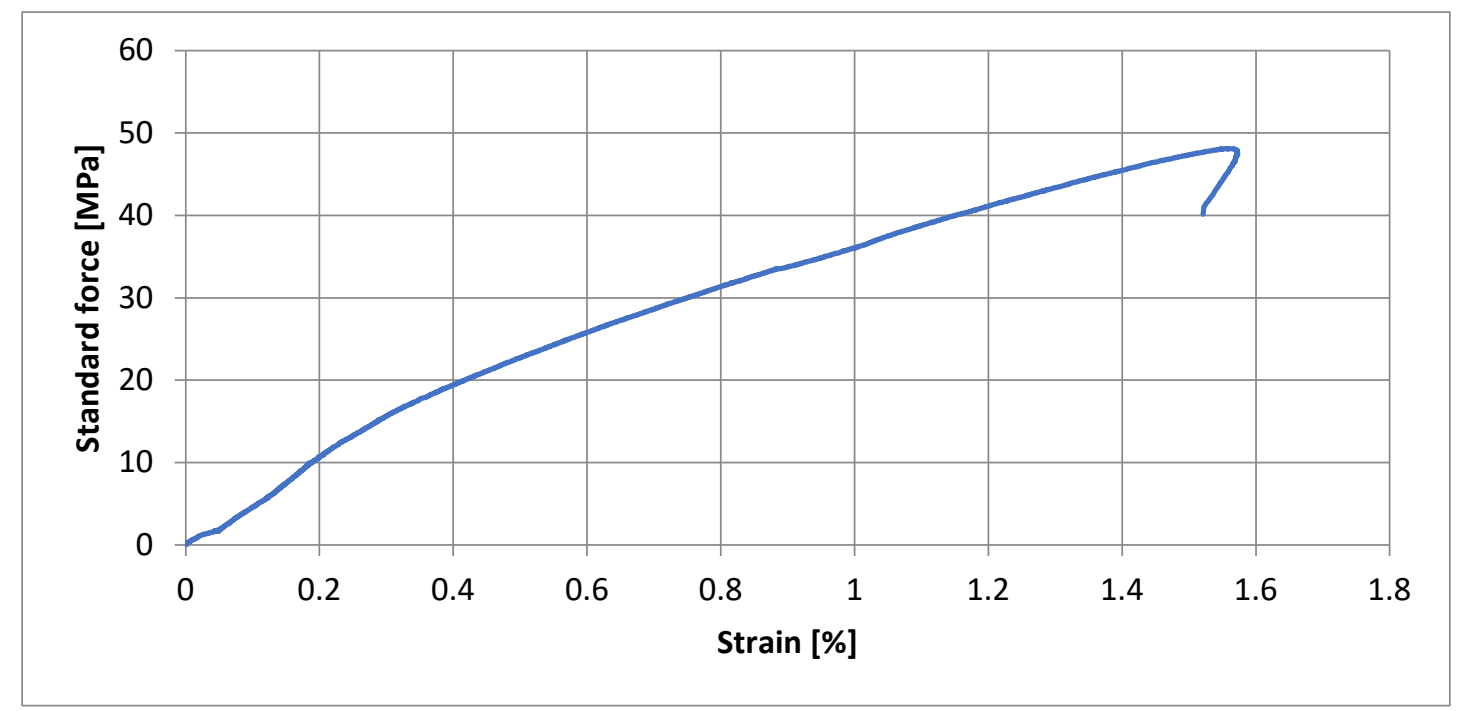

Fig.33 Standard Force vs Strain graph of PP + K.F samples

\section{Sample 2 : Poly Propylene (with Basalt D.B.F)}

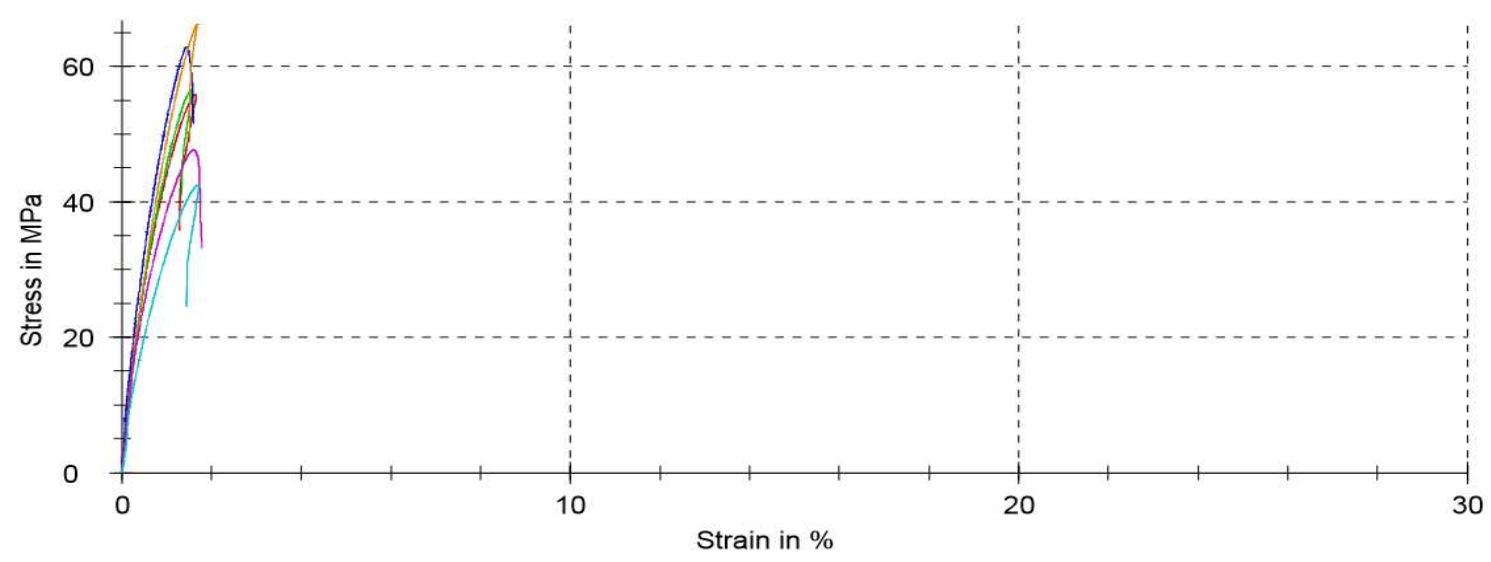

Fig.34 Stress-Strain graph of PP + D.B.F samples

\begin{tabular}{|c|c|c|c|}
\hline Specimen No. & $\sigma$ low (MPa) & $\sigma$ High (MPa) & Et (MPa) \\
\hline 1. & 3.577 & 16.27 & 6754.42 \\
\hline 2. & 2.860 & 15.89 & 6882.67 \\
\hline 3. & 3.640 & 19.08 & 7307.67 \\
\hline 4. & 2.908 & 16.01 & 6809.90 \\
\hline 5. & 3.181 & 15.58 & 6692.27 \\
\hline 6. & 1.905 & 12.34 & 5793.92 \\
\hline
\end{tabular}

Table.12 Experimental values of PP + D.B.F samples 


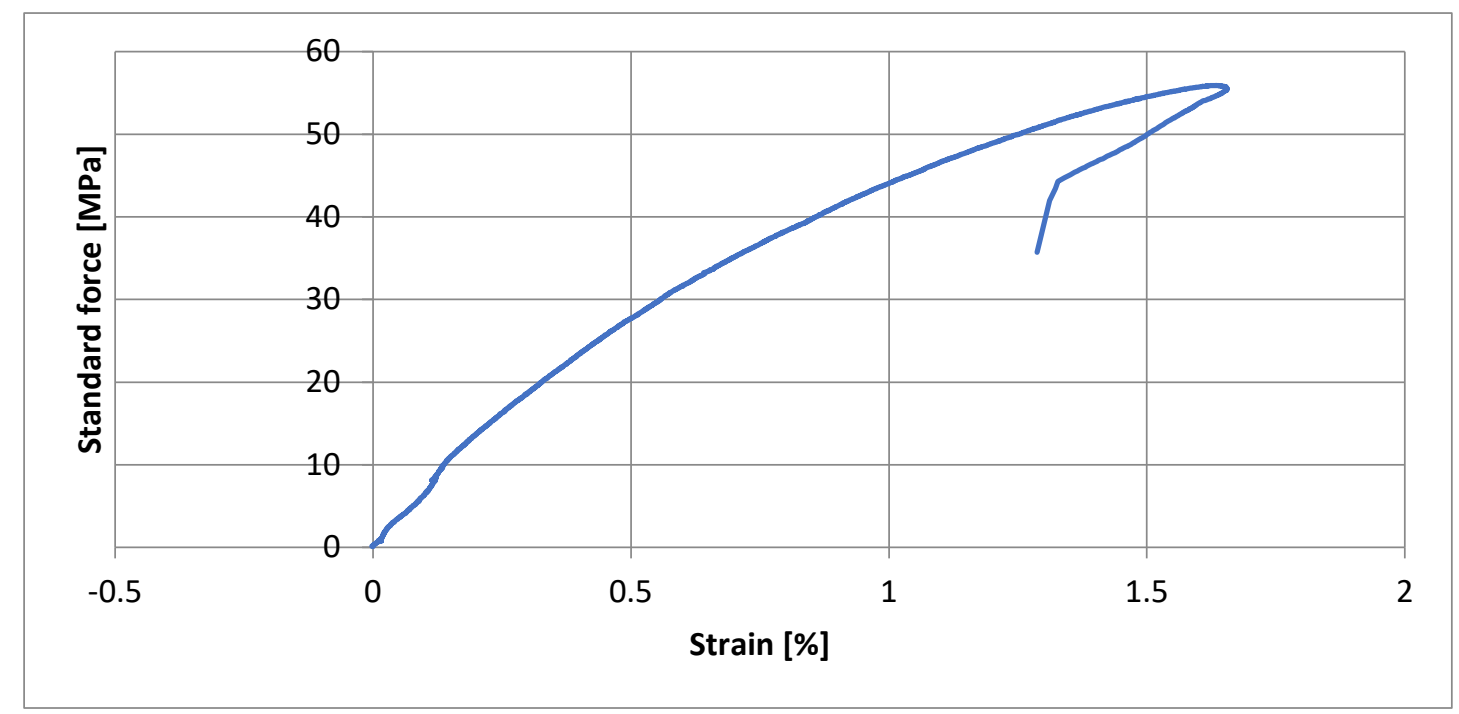

Fig.35 Standard Force vs Strain graph of PP + D.B.F samples

\section{Sample 3 : Poly Propylene (with Basalt F.T)}

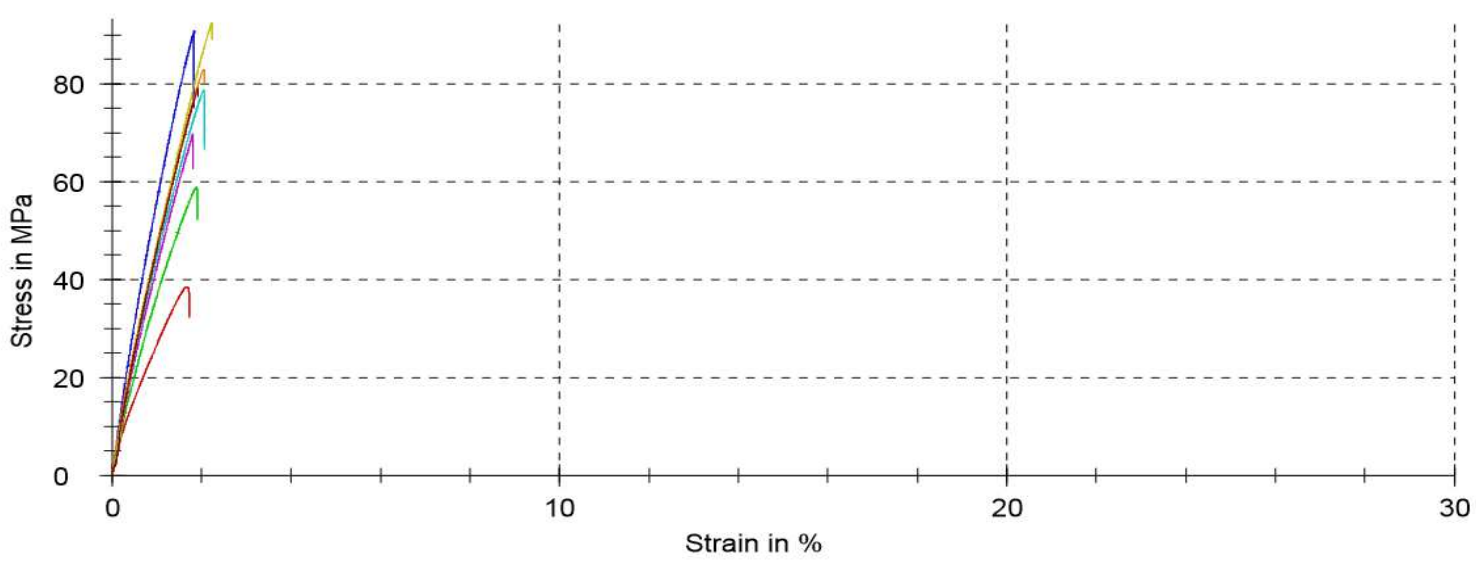

Fig.36 Stress-Strain graph of PP + F.T samples

\begin{tabular}{|c|c|c|c|}
\hline Specimen No. & $\sigma$ low (MPa) & $\sigma$ High (MPa) & Et (MPa) \\
\hline 1. & 1.465 & 9.161 & 4193.71 \\
\hline 2. & 2.038 & 10.880 & 4588.14 \\
\hline 3. & 2.428 & 16.123 & 6887.87 \\
\hline 4. & 3.007 & 14.252 & 5678.02 \\
\hline 5. & 1.868 & 11.951 & 5079.50 \\
\hline 6. & 2.060 & 12.740 & 5435.59 \\
\hline 7. & 1.793 & 12.467 & 5312.78 \\
\hline 8. & 1.688 & 12.818 & 6629.01 \\
\hline
\end{tabular}

Table.13 Experimental values of PP + F.T samples 


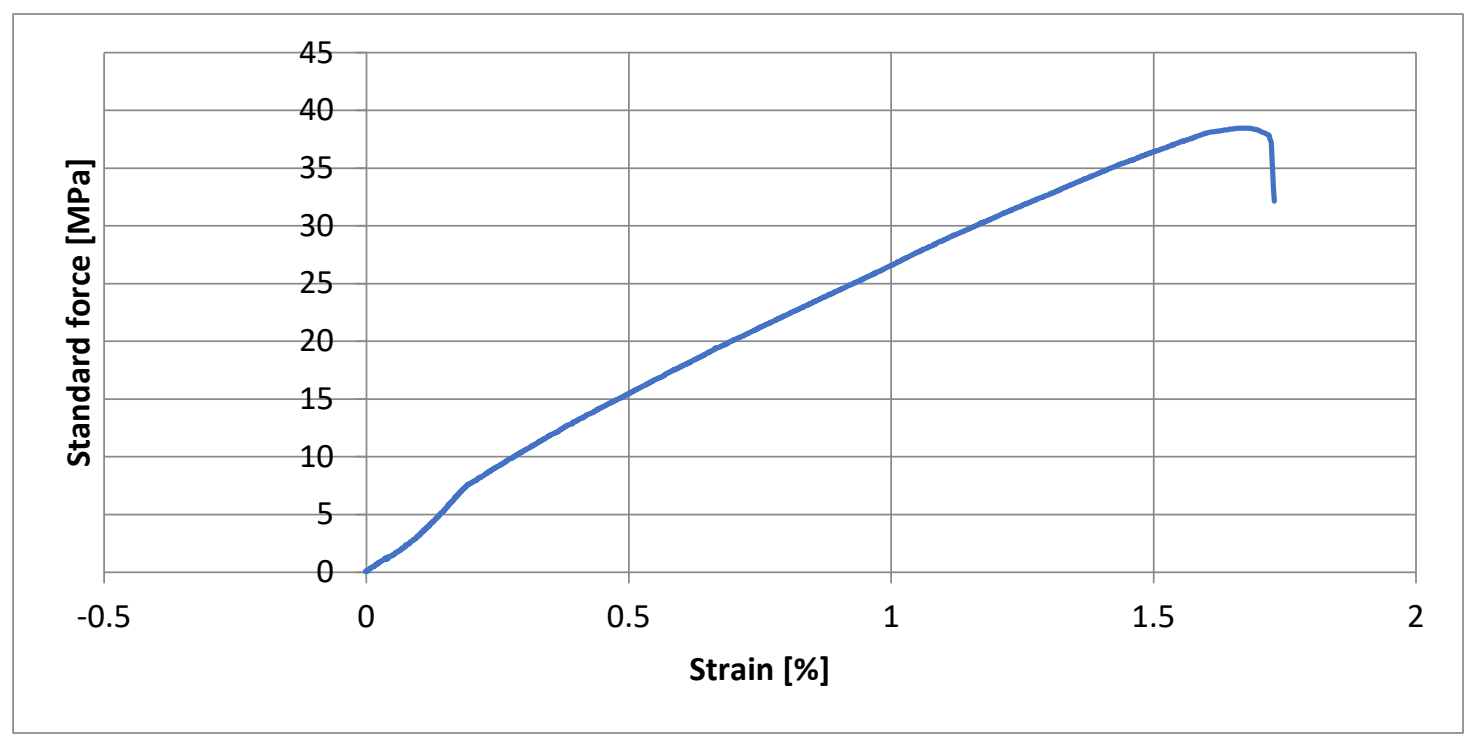

Fig.37 Standard Force vs Strain graph of PP + F.T samples

\section{Comparison of Tensile test results}

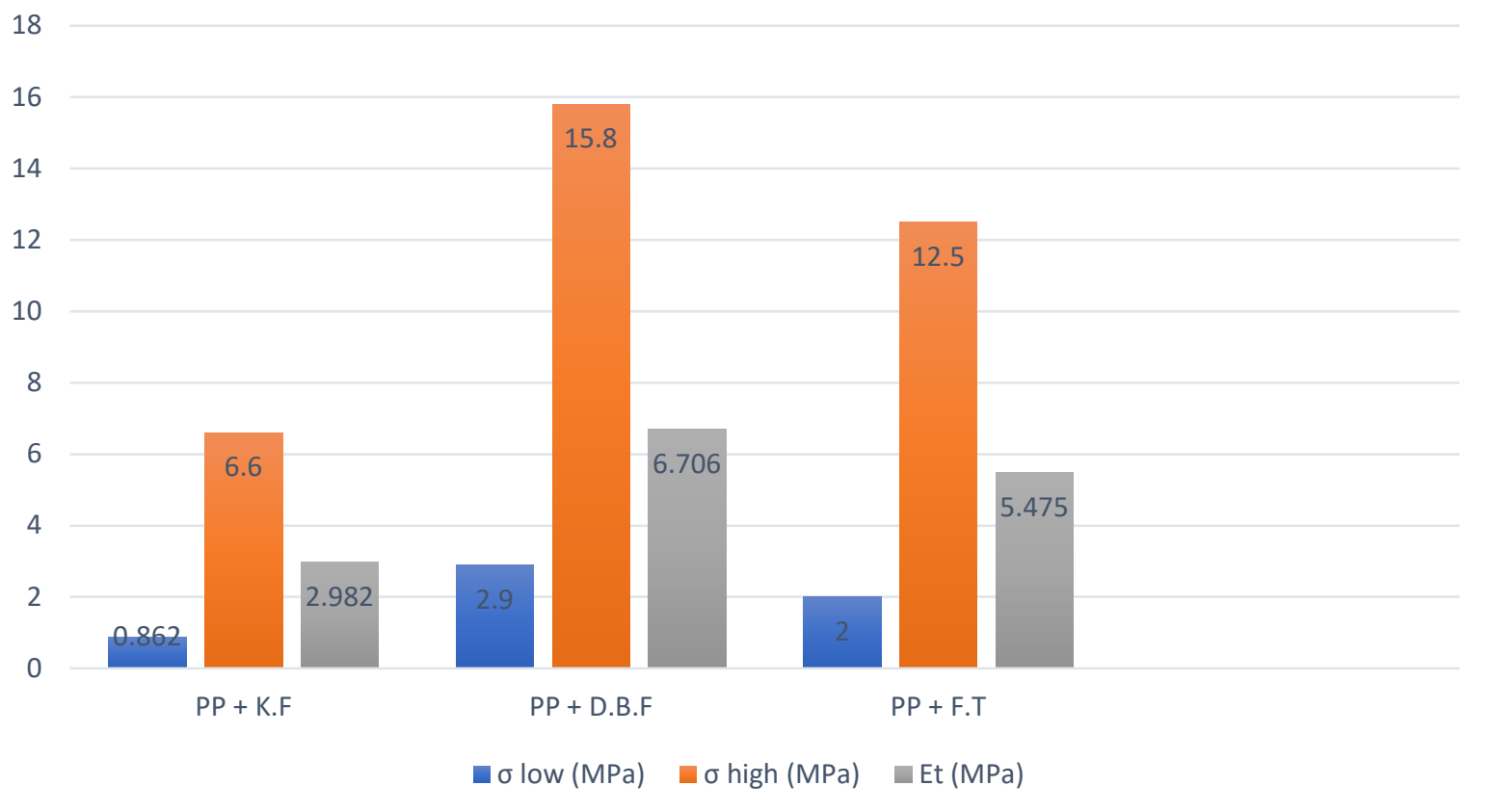

All mechanical properties show a gradual increase by the increase of basalt content. 


\section{CHARPY IMPACT TEST:}

Sample 1 : Poly Propylene (PP + K.F)

\begin{tabular}{|c|c|c|c|c|c|c|c|c|}
\hline Sample No. & $\begin{array}{c}\mathbf{L} \\
(\mathbf{m m})\end{array}$ & $\begin{array}{c}\mathbf{B} \\
(\mathbf{m m})\end{array}$ & $\begin{array}{c}\mathbf{H} \\
(\mathbf{m m})\end{array}$ & $\begin{array}{c}\text { Mass } \\
(\mathbf{g})\end{array}$ & $\begin{array}{c}\mathbf{A w} \\
(\mathbf{g} / \mathbf{m} \mathbf{2})\end{array}$ & $\begin{array}{c}\mathbf{D} \\
(\mathbf{g} / \mathbf{c m 3})\end{array}$ & $\begin{array}{c}\mathbf{E} \\
(\mathbf{K J} / \mathbf{m} \mathbf{2})\end{array}$ & SP IE \\
\hline 1. & 79.10 & 14.90 & 1.50 & 1.61 & 1368.92 & 0.91 & 28.56 & 32.45 \\
\hline 2 & 79.70 & 14.80 & 1.50 & 1.56 & 1320.15 & 0.88 & 26.22 & 33.07 \\
\hline 3. & 79.80 & 14.30 & 1.60 & 1.45 & 1268.91 & 0.79 & 23.24 & 30.85 \\
\hline 4. & 78.40 & 14.60 & 1.60 & 1.38 & 1205.62 & 0.75 & 27.71 & 31.19 \\
\hline 5. & 79.20 & 14.30 & 1.60 & 1.61 & 1421.56 & 0.89 & 32.56 & 33.66 \\
\hline 6. & 79.30 & 14.60 & 1.50 & 1.68 & 1451.05 & 0.97 & 30.06 & 30.89 \\
\hline 7. & 80.10 & 13.40 & 1.80 & 1.88 & 1751.54 & 0.97 & 28.39 & 30.31 \\
\hline 8. & 79.60 & 15.50 & 1.80 & 2.08 & 1685.85 & 0.94 & 34.50 & 35.46 \\
\hline 9. & 79.50 & 15.30 & 1.80 & 2.13 & 1751.14 & 0.97 & 36.54 & 34.45 \\
\hline 10. & 79.30 & 14.20 & 1.70 & 2.03 & 1802.75 & 1.06 & 34.24 & 33.56 \\
\hline Mean & $\mathbf{7 9 . 4 0}$ & $\mathbf{1 4 . 5 9}$ & $\mathbf{1 . 6 4}$ & $\mathbf{1 . 7 4}$ & $\mathbf{1 5 0 2 . 7 5}$ & $\mathbf{0 . 9 1}$ & $\mathbf{2 9 . 7 5}$ & $\mathbf{3 2 . 0 0}$ \\
\hline S & 0.46 & 0.60 & 0.13 & 0.27 & 223.76 & 0.09 & 4.16 & 1.80 \\
\hline S (\%) & 0.58 & 4.09 & 7.71 & 15.51 & 14.89 & 9.92 & 14.0 & 5.56 \\
\hline
\end{tabular}

Table.14 Experimental values of PP + K.F samples

Sample 2 : Poly Propylene (with Basalt D.B.F)

\begin{tabular}{|c|c|c|c|c|c|c|c|c|}
\hline Sample No. & $\begin{array}{c}\mathbf{L} \\
(\mathbf{m m})\end{array}$ & $\begin{array}{c}\mathbf{B} \\
(\mathbf{m m})\end{array}$ & $\begin{array}{c}\mathbf{H} \\
\mathbf{( m m})\end{array}$ & $\begin{array}{c}\text { Mass } \\
\mathbf{( g )}\end{array}$ & $\begin{array}{c}\mathbf{A w} \\
\mathbf{( g / m 2})\end{array}$ & $\begin{array}{c}\mathbf{D} \\
(\mathbf{g} / \mathbf{c m} \mathbf{m})\end{array}$ & $\begin{array}{c}\mathbf{E} \\
(\mathbf{K J} / \mathbf{m} \mathbf{2})\end{array}$ & $\mathbf{S P ~ I E}$ \\
\hline 1. & 79.60 & 14.90 & 1.70 & 1.32 & 1112.95 & 0.65 & 23.69 & 36.18 \\
\hline 2 & 79.00 & 14.90 & 1.50 & 1.27 & 1078.92 & 0.72 & 23.80 & 33.09 \\
\hline 3. & 80.00 & 14.20 & 1.50 & 1.30 & 1144.37 & 0.76 & 59.25 & 34.08 \\
\hline 4. & 79.30 & 14.20 & 1.70 & 1.20 & 1065.66 & 0.63 & 18.27 & 29.14 \\
\hline 5. & 78.80 & 14.70 & 1.50 & 1.17 & 1010.05 & 0.67 & 19.24 & 28.57 \\
\hline 6. & 79.40 & 14.90 & 1.50 & 1.36 & 1149.56 & 0.77 & 28.04 & 36.59 \\
\hline 7. & 80.40 & 14.80 & 1.80 & 1.28 & 1075.70 & 0.60 & 16.59 & 27.76 \\
\hline 8. & 79.60 & 15.80 & 1.90 & 1.43 & 1137.01 & 0.60 & 32.98 & 29.18 \\
\hline 9. & 79.50 & 13.90 & 1.90 & 1.30 & 1176.42 & 0.62 & 23.59 & 38.10 \\
\hline 10. & 78.80 & 13.90 & 1.80 & 1.30 & 1186.87 & 0.66 & 28.98 & 43.95 \\
\hline Mean & $\mathbf{7 9 . 5 3}$ & $\mathbf{1 4 . 7 1}$ & $\mathbf{1 . 7 2}$ & $\mathbf{1 . 4 0}$ & $\mathbf{1 1 9 0 . 3 2}$ & $\mathbf{0 . 6 9}$ & $\mathbf{2 7 . 4 4}$ & $\mathbf{4 1 . 0 0}$ \\
\hline S & 0.50 & 0.57 & 0.17 & 0.26 & 196.27 & 0.09 & 12.28 & 15.40 \\
\hline S (\%) & 0.63 & 3.85 & 10.19 & 18.52 & 16.49 & 13.06 & 44.74 & 37.92 \\
\hline
\end{tabular}

Table.15 Experimental values of PP + D.B.F samples 
Sample 3 : Poly Propylene (with Basalt F.T)

\begin{tabular}{|c|c|c|c|c|c|c|c|c|}
\hline Sample No. & $\begin{array}{c}\mathbf{L} \\
(\mathbf{m m})\end{array}$ & $\begin{array}{c}\mathbf{B} \\
(\mathbf{m m})\end{array}$ & $\begin{array}{c}\mathbf{H} \\
\mathbf{( m m})\end{array}$ & $\begin{array}{c}\text { Mass } \\
\mathbf{( g )}\end{array}$ & $\begin{array}{c}\mathbf{A w} \\
\mathbf{( g / m 2})\end{array}$ & $\begin{array}{c}\mathbf{D} \\
(\mathbf{g} / \mathbf{c m} \mathbf{m})\end{array}$ & $\begin{array}{c}\mathbf{E} \\
(\mathbf{K J} / \mathbf{m} \mathbf{2})\end{array}$ & $\mathbf{S P ~ I E}$ \\
\hline 1. & 79.30 & 15.00 & 1.90 & 2.10 & 1765.45 & 0.93 & 32.14 & 34.59 \\
\hline 2 & 79.60 & 13.90 & 1.80 & 1.90 & 1717.22 & 0.95 & 37.97 & 39.80 \\
\hline 3. & 79.50 & 15.00 & 1.80 & 2.04 & 1710.22 & 0.95 & 37.26 & 39.20 \\
\hline 4. & 79.40 & 15.20 & 1.90 & 1.49 & 1234.59 & 0.65 & 23.51 & 36.18 \\
\hline 5. & 80.00 & 14.90 & 1.90 & 1.70 & 1426.17 & 0.76 & 33.19 & 43.50 \\
\hline 6. & 79.30 & 14.70 & 1.90 & 1.69 & 1449.76 & 0.60 & 32.46 & 54.37 \\
\hline 7. & 78.90 & 14.30 & 1.90 & 1.28 & 1134.48 & 0.68 & 23.04 & 33.90 \\
\hline 8. & 80.00 & 14.20 & 1.80 & 1.39 & 1223.59 & 0.68 & 26.00 & 38.24 \\
\hline 9. & 79.30 & 14.90 & 1.90 & 1.15 & 973.28 & 0.51 & 19.60 & 38.27 \\
\hline 10. & 79.80 & 14.30 & 1.80 & 1.23 & 1077.87 & 0.60 & 20.67 & 34.52 \\
\hline Mean & $\mathbf{7 9 . 5 1}$ & $\mathbf{1 4 . 6 4}$ & $\mathbf{1 . 8 6}$ & $\mathbf{1 . 6 0}$ & $\mathbf{1 3 7 1 . 3 1}$ & $\mathbf{0 . 7 3}$ & $\mathbf{2 8 . 5 8}$ & $\mathbf{3 9}$ \\
\hline S & 0.35 & 0.43 & 0.05 & 0.34 & 286.84 & 0.16 & 6.82 & 6.06 \\
\hline S (\%) & 0.44 & 2.95 & 2.78 & 21.38 & 20.92 & 22.01 & 23.86 & 15.45 \\
\hline
\end{tabular}

Table.16 Experimental values of PP + F.T samples

\section{Comparison of Specific Impact Energy}

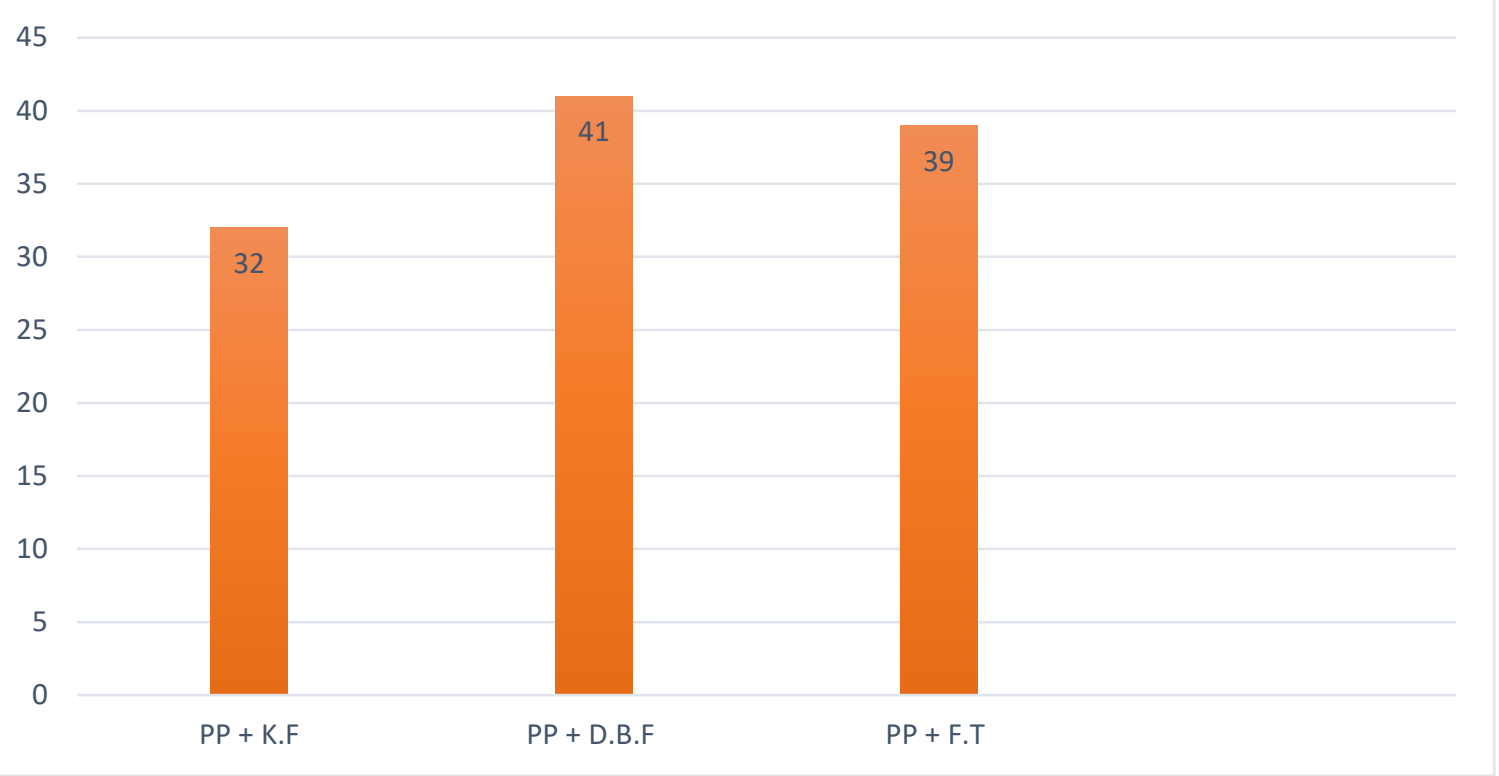

Not just tensile and flexural properties, basalt fibers have improved simultaneously the energy absorption of the composites. 


\section{Conclusion}

Successful production of homogenous fiber mats with evenly distributed fibers. SEM analysis of the samples confirmed the quality of fiber mats.

$>$ Compression molded test specimens were analysed for their mechanical properties.

$>$ Basalt fibers were gradually introduced into the plant fiber reinforced polypropylene. The mechanical properties manifest significantly increase by the increasing concentration of basalt fibers.

$>$ Basalt fibers have excellent potential to improve the mechanical performance of NF reinforced composites without reducing their renewable material content.

> Hybrid bast and bast polymer composites have great potential to replace, if not fully, but partially, non-renewable fiber reinforced polymer composites in structural, load bearing and shock absorption applications.

$>$ It can be inferred from the above test results that basalt fibers of D.B.F have greater improvement in the tensile and flexural properties; energy absorption of the composites compared to other samples. 


\section{References}

[1] T. G. H. H. K. R. L. M. W. I. Kenneth S. Whiteley, "Polyolefins," in Ullmann's Encyclopedia of Industrial Chemistry. Ullmann's Encyclopedia of Industrial Chemistry. , 2005.

[2] T. E. C. industry, http://www.essentialchemicalindustry.org/polymers/polypropene.html, 2016.

[3] D. Tripathi, Practical guide to polypropylene. Shrewsbury: RAPRA Technology., ISBN 9781859572825, 2001.

[4] C. Maier and T. Calafut, Polypropylene: the definitive user's guide and databook, 1998.

[5] W. Kaiser, Kunststoffchemie für Ingenieure von der Synthese bis zur Anwendung [Plastics chemistry for engineers from synthesis to application] (in German) (3rd ed.), München: Hanser. p. 247. ISBN 978-3-446-43047-1., 2011.

[6] v. S. Nuyken, M. Koltzenburg and O. Maskos, Polymere: Synthese, Eigenschaften und Anwendungen [Polymers: synthesis, properties and applications] (in German) (1st ed.)., Springer. ISBN 978-3-642-34772-6., 2013.

[7] Webster's Third New International Dictionary, Unabridged. Merriam-Webster, http://unabridged.merriam-webster.com, 2002.

[8] https://en.wikipedia.org/wiki/Flax\#Flax_fibers, "Flax fibers".

[9] https://en.wikipedia.org/wiki/Basalt_fiber, "Basalt Fiber".

[10] P. D. Stadnicki, "Optimisation of selected components of a roller carding machine in the aspect of improving their cooperation quality," January 2015.

[11] "https://textilelearner.blogspot.com/2012/01/needle-punching-process-application.html," in Needle Punching Process / Application Needle Punching / Market and Prospects of Needle Punching.

[12] R. H. D. K. A. a. L. A. Todd, "Manufacturing Processes Reference Guide," 1993.

[13] H. Czichos, " Springer Handbook of Materials Measurement Methods," 2006.

[14] M. M. A and C. K. Kumar, "Mechanical Behaviors of Materials," Prentice Hall. ISBN 978-0-13262817-4., 1998. 